\title{
NEUROIMAGING METHODS FOR ASSESSMENT OF CORTICAL AUDITORY PROCESSING: A REVIEW \\ Contributions:
} A Study design/planning B Data collection/entry C Data analysis/statistics D Data interpretation E Preparation of manuscript F Literature analysis/search $\mathrm{G}$ Funds collection

\section{Katarzyna CieślaE-F, Bartosz Kochańskie-F, Paulina Paluch ${ }^{\mathrm{E}-\mathrm{F}}$, Tomasz Wolak ${ }^{\mathrm{E}-\mathrm{F}}$}

Bioimaging Research Center, World Hearing Center, Institute of Physiology and Pathology of Hearing, Poland

This article was written on the basis of equal authorship; all authors have contributed equally to its preparation.

Corresponding author: Tomasz Wolak; Bioimaging Research Center, World Hearing Center, Institute of Physiology and Pathology of Hearing, Mochnackiego 10, 02-042 Warsaw, Poland; email: t.wolak@ifps.org.pl; Phone: +48 223560349

\begin{abstract}
In this review we describe several methods that can be used to study auditory processing in the cerebral cortex, including functional magnetic resonance imaging (fMRI), magnetoencephalography (MEG), electroencephalography (EEG), functional near-infrared spectroscopy (fNIRS), and positron emission tomography (PET). We explain the principles of each technique and list the characteristics that make them suitable for certain research applications. For each method we give a broad range of examples that have already helped uncover various aspects of cortical auditory processing. We compare and summarise the characteristics of each method in order to help the reader choose one that is best suited to answer a specific research question. We also give perspectives on multimodal imaging - collecting functional brain data with two or more techniques during one study - as a means for overcoming the limitations of each method alone by examining complementary information. This article aims to be a short introductory guide and source of reference for researchers in the field of auditory neuroimaging.
\end{abstract}

Key words: magnetic resonance imaging $\bullet$ near-infrared spectroscopy $\bullet$ electroencephalography $\bullet$ positron-emission tomography $\bullet$ auditory cortex • magnetoencephalography

\section{PRZEGLĄD METOD NEUROOBRAZOWYCH DO OCENY PROCESÓW PRZETWARZANIA SŁUCHOWEGO W KORZE MÓZGU}

\section{Streszczenie}

Niniejszy artykuł stanowi wprowadzenie do metod neuroobrazowych oferujących możliwości badania procesów przetwarzania informacji słuchowych w korze mózgu - funkcjonalnego obrazowania metodą rezonansu magnetycznego (fMRI - ang. functional magnetic resonance imaging), magnetoencefalografii (MEG), elektroencefalografii (EEG), funkcjonalnej spektroskopii bliskiej podczerwieni (fNIRS - ang. functional near-infrared spectroscopy) oraz pozytonowej tomografii emisyjnej (PET - ang. positron emission tomography). W artykule wyjaśniono podstawy każdej z technik oraz cechy charakterystyczne predysponujące każdą z nich do konkretnych zastosowań badawczych. Dla każdej z metod wymieniony jest szereg przykładów dotychczasowych zastosowań w badaniu procesów przetwarzania słuchowego. Wprowadzenie do metod zakończone jest ich porównawczym podsumowaniem mającym na celu wspomóc proces decyzyjny doboru metody optymalnej do uzyskania odpowiedzi na określone pytanie badawcze. Przedyskutowane są również perspektywy obrazowania multimodalnego - podejścia opierającego się na zbieraniu danych neuroobrazowych za pomocą dwóch lub większej ilości metod obrazowych w ramach jednego badania - jako sposobu kompensacji ograniczeń prezentowanych przez metody stosowane pojedynczo oraz formy uzupełnienia zbieranej informacji. Artykuł może być traktowany jako krótki przewodnik wprowadzający do tematyki oraz źródło referencji literaturowych dla badaczy w dziedzinie obrazowania funkcjonalnego procesów przetwarzania słuchowego.

Słowa kluczowe: kora słuchowa • elektroencefalografia • magnetoencefalografia $\bullet$ funkcjonalne obrazowanie metodą rezonansu magnetycznego $\bullet$ funkcjonalna spektroskopia bliskiej podczerwieni $\bullet$ pozytonowa tomografia emisyjna

\section{Introduction}

The human auditory system is extremely complex and consists of a number of integrally connected peripheral and central parts. After entering the external ear, acoustic signals travel via the middle ear and, after conversion to neural signals in the inner ear, undergo various stages of processing as they travel via a sequence of brainstem nuclei, subcortical structures, and finally to the cortex [1]. Several methods for assessing the function of structures peripheral to the cortex have already been developed as tools in basic research and clinical examination [2]. Biopotentials, reflecting the activity of sequential gray matter nuclei in the auditory pathway, are one of the most often applied measurement methods (Figure 1), with measurements of auditory brainstem responses (ABRs) being a prominent example [3,4].

In terms of research applications, recent years have seen tremendous advances in neuroimaging techniques for functional assessment of the central auditory system and 


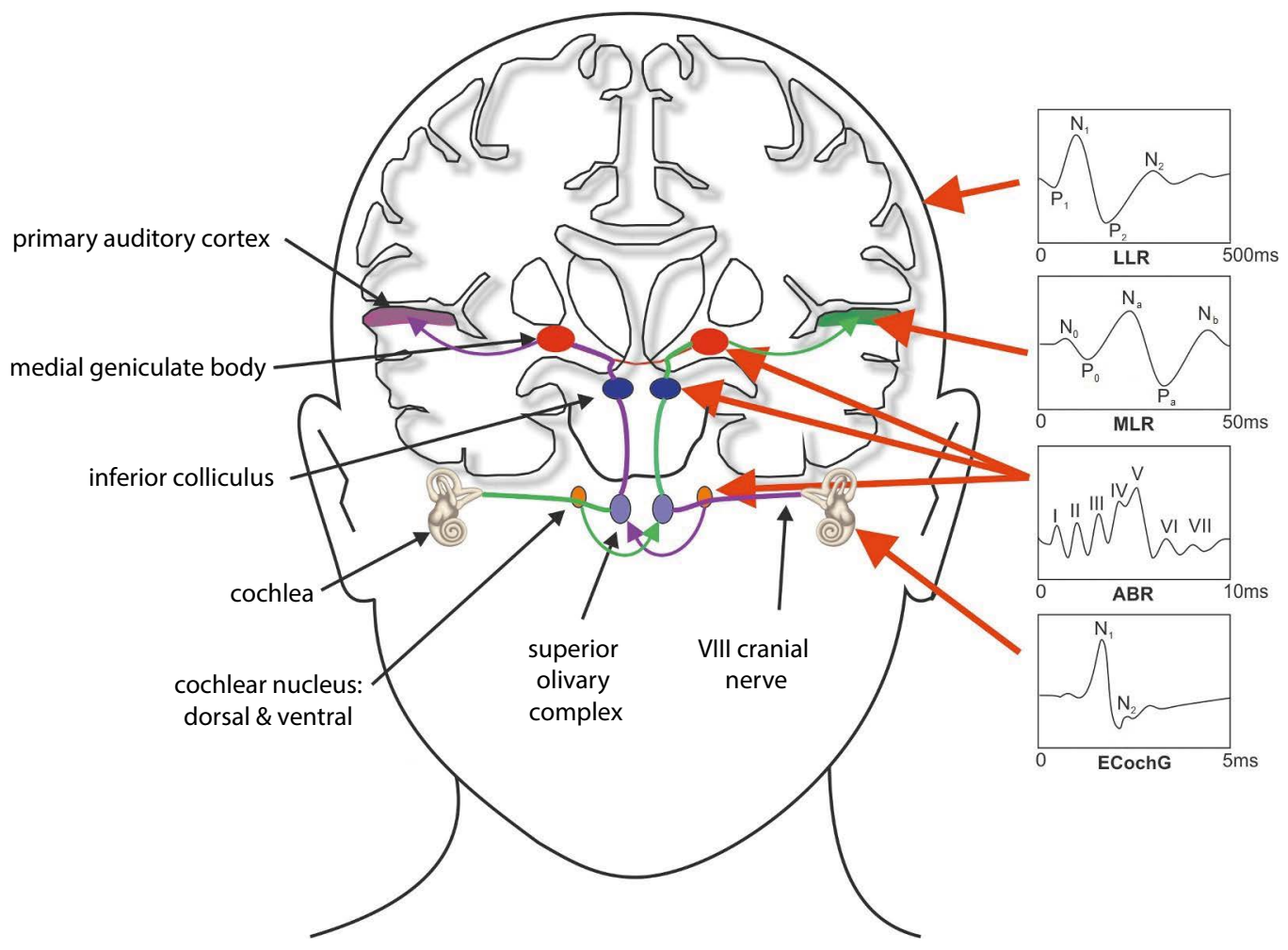

Figure 1. Biopotentials generated in the auditory pathway: LLR (late-latency responses) - responses from auditory cortex, latency of 50-300 ms; MLR (medium-latency responses, latency of 12-50 ms); ABR (Auditory Brainstem Responses, early potentials, latency of 1-12 ms); ECochG (electrocochleographic responses, latency circa $1.5 \mathrm{~ms}$ )

especially the processing of acoustic signal in the brain. The most commonly applied scientific methods include those based on measurement of the electromagnetic responses of cortical neurons: electroencephalography (EEG), magnetoencephalography (MEG), and methods for measuring hemodynamic responses secondary to neuronal responses, such as functional magnetic resonance (fMRI) and near infrared spectroscopy (NIRS). Yet another neuroimaging technique is positron emission tomography (PET) which measures biochemical processes in the brain (or other part of the body), including hemodynamics, gray matter metabolism, and function of neuroreceptors.

In the following sections we discuss the technical fundamentals of each of these methods and the biological phenomena they measure, since the methods differ in a number of features. They are sensitive to different representations of the original neural activity occurring in the brain, and provide various ranges of spatial resolution (the minimum difference in location the method can provide) and temporal resolution (the minimum difference in time). Both types of resolution depend on a combination of several factors, including characteristics of the equipment, underlying physiological processes, and the experimental design used; when all these factors are taken into account, the resulting "effective resolution" is determined by the most limiting factor. This review discusses these and other matters and shows examples of how each method can be applied to study cortical auditory processing; hopefully it will assist the reader in choosing an optimal method to answer a specific research question. The review may be treated as an introductory guide and a reference source for researchers venturing into the field of auditory neuroimaging.

\section{Electroencephalography and magnetoencephalography}

\section{Principles of the methods and technical parameters}

Electroencephalography (EEG) and magnetoencephalography (MEG) are non-invasive techniques of measuring brain activity, represented by electric potentials (EEG) and magnetic fields (MEG) observed outside a subject's skull $[5,6]$. The signals measured in EEG and MEG originate from ion currents directly associated with neural activity. Single neurons, however, generate signals too weak to be measured. Therefore most of the signal observed by these techniques comes from the simultaneous firing of populations of neurons with uniform spatial orientation - as in the case of the pyramidal neurons in the cortex. Not every kind of neural activity is detectable in the signal, with postsynaptic potentials comprising most of what is observed [7].

The measurement of neural activity as defined above nevertheless still poses a challenge, and requires sensitive equipment and attention to details during signal acquisition. In EEG one measures electric potentials from the head by means of electrodes attached to the scalp, usually with the aid of an elastic cap, and connected to a signal amplifier (Figure 2B). The amplitude of the signal of interest is up 
to 100 microvolts $(100 \mu \mathrm{V})$. The electrodes used in EEG vary in material and in the scalp-electrode contact method (typically saline solution or electroconductive gel) [8]. MEG, on the other hand, utilizes magnetic field sensors, typically based on superconducting quantum interference device (SQUID) technology. In the standard setup, magnetic fields are measured a short distance from the head (up to $2 \mathrm{~cm}$ ) since the sensors, due to the need for cooling, must be enclosed in a heavy immobile vacuum container (Figure 2A) [9]. Magnetic field strengths from the brain, as measured by MEG, reach up to several hundred femtotesla (fT), i.e. far below common urban electromagnetic noise levels which are six orders of magnitude larger. This means that an MEG device - in contrast to EEG - needs to be operated in a special magnetically shielded room.

There are a considerable number of noise sources that affect both EEG and MEG signals. The signal can be contaminated by both environmental electromagnetic noise and electrical disturbances caused by physiological effects (including facial muscle contractions, eye movements, and heart activity). It is therefore best if the researcher evaluates, minimises, and accounts for noise sources likely to be present during signal acquisition. A broad literature exists on ways of identifying and removing all types of noise from EEG/MEG data [6,9-11].

Importantly, EEG and MEG measure two physical derivatives of the same original neural activity; they differ in some respects, but the methods are actually complementary rather than interchangeable. For example, MEG and EEG have different sensitivities to the signal depending on location and orientation of the underlying neural generators. MEG is less sensitive to sources placed deeper and oriented perpendicularly to the surface of the skull. Selective sensitivity may be an advantage or disadvantage depending on the situation. For example, MEG allows the signal of interest to be less masked by background neural activity if the signal is expected to come from the sulci. In other settings, MEG may have difficulty detecting the activity of interest. Another difference between EEG and MEG becomes apparent when one wishes to localise a neural source underlying an observed scalp-related signal. EEG is largely affected by volume conduction effects related to the properties of head tissues, and so requires detailed knowledge of the subject's head anatomy to accurately reconstruct sources. On the other hand, MEG requires less detailed anatomical information because there is only a weak interaction between any magnetic field of interest and head tissue $[6,12]$.

A characteristic common to both MEG and EEG is relatively good temporal resolution. Neural processes in the brain occur in temporal windows as short as tens to hundreds of milliseconds, although some phenomena (like processing of directional hearing cues in sound localisation) may occur even faster [13]. Thanks to the fact that MEG and EEG pick up direct representations of ongoing neural activity, it is possible - with appropriate signal sampling - to probe activity in virtually all of these time windows. Most scientific-grade EEG and MEG equipment provides sampling of $1 \mathrm{kHz}$ or better, providing temporal resolution not available with any other neuroimaging method. Such sampling rates are very useful in practical experimental applications, allowing one to study neural

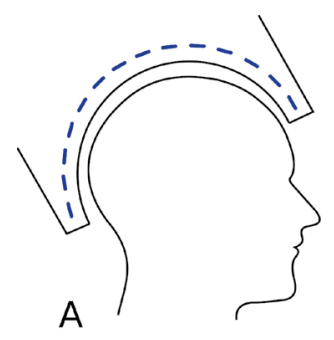

B

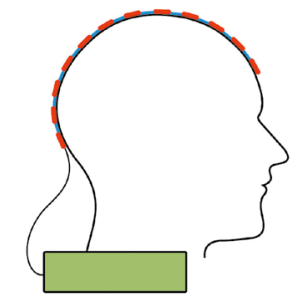

Figure 2. Cross-section of a standard MEG measurement setup (A) and standard EEG setup (B). In the MEG setup, recording sites are marked in blue and sensors are enclosed within a vacuum flask. In the EEG setup, the electrodes (red) are fastened to a cap (blue) and connected to a signal amplifier (green)

activity between stimulus and response, assess neural activity synchronized with short stimuli, and track neural processing of ongoing phenomena (e.g. speech) in real time. Access to real-time, non-delayed representations of neural activity is a great advantage of both EEG and MEG [14].

Both EEG and MEG are comparable in terms of spatial resolution. For EEG, systems utilizing as few as 21 or 32 electrodes may still be encountered, but more advanced setups with as many as 128 or 256 electrodes are available and are now preferred $[15,16]$. In MEG the number of individual locations around the scalp varies across devices. The number can be as high as 275, but MEG devices may additionally utilize multiple layers of sensors or multiple sensors in one location $[17,18]$. Ultimately, the center-to-center distance between sensors in most currently used EEG and MEG systems is not much less than $2 \mathrm{~cm}$.

It can therefore be concluded that the spatial information available in both MEG and EEG is limited. There are several contributing factors. Most importantly, the signal is measured at the scalp, not in the head volume. This means that it is difficult to accurately relate the observed activity of interest to a certain anatomical structure. Nevertheless, topographic analysis of spatial distributions of the signal as observed on the scalp can be performed and provides important information about neural processes [16]. For both methods there is also some amount of signal blur that may occur due to properties of the tissue - most pronounced in EEG - as well as the distance from the scalp to the source of interest (i.e. the brain region generating the signal) [19]. This results in deterioration of effective spatial resolution; however it has been shown that a reduced EEG inter-electrode distance of $1 \mathrm{~cm}$ makes it possible to observe new spatial features, the implication being that there is still room for technological improvement [20]. Nevertheless, with increased sensor density, the manufacturing process becomes more difficult and expensive. Moreover, for EEG systems (in which gel is applied to each electrode after fitting the subject with a cap), additional sensors mean increased time for preparing the subject, possibly to the extent that it is becomes impractical.

In discussing the spatial characteristics of MEG and EEG it is worth noting there are several methods which aim to estimate, via computational algorithms, the exact intracranial source of neural activity observed as signals on 
the scalp [21,22]). These source reconstruction techniques allow one to establish a more direct relation between the EEG or MEG signal and underlying anatomical structures, and thus allow fusion of the acquired results with other neuroimaging techniques, such as fMRI. However, the user needs to be aware that these algorithms require certain assumptions in order to work [21]. The resolution and accuracy of source localisation depends on multiple factors and the choice of the method. Typically, the resolution lies in the range of one to several centimeters [23].

Both EEG and MEG are undergoing continual development in terms of equipment and methods of signal analysis. Both techniques are also becoming more mobile. For EEG, wireless mobile amplifiers are now available [24]. For MEG, room temperature magnetic field sensors are being developed, cutting out the need for constant liquid helium cooling and thus making the equipment less bulky. The new MEG systems also provide the opportunity for on-scalp sensor placement, which, by measuring closer to the source of neural activity, improves signal quality $[25,26]$. In addition, methods and equipment for exact measurement of EEG electrode positions are being developed that make spatial inferences (defining where exactly the signal comes from in the brain) more precise compared to the commonly used brain template based on a population mean $[27,28]$. Also a new branch of Ear-EEG and cEEG grid devices is emerging that relies on acquisition of brain signals from electrodes placed only in or around the ears, thus increasing the wearability and mobility of the equipment and making long-term measurements in natural environments more feasible [29-31].

\section{General applications and applications in auditory research}

In general, EEG and MEG are used when temporal information and access to direct electrical representations of activity of neural populations are important. Some fields of science, medicine, and engineering have developed considerable interest in EEG and MEG because of these advantages, in the process providing a considerable body of cases and methodological advances which auditory neuroscience researchers can benefit from. One distinctive application of both methods - diagnosis of epilepsy - benefits from the ability to reveal even subtle temporal abnormalities in recorded signals [32]. Both EEG and MEG can be used in neurofeedback studies and related therapies, providing the participant with real-time feedback on certain aspects of their brain activity and allowing them to try and learn how to modulate it $[33,34]$. EEG and MEG also find applications in brain-computer interface (BCI) systems which allow paralyzed patients, for example, to communicate with other people and interact with smart electronic devices [35]. Additionally, EEG is extensively used in sleep research and diagnostics as it does not impose strict constraints on the person's position during study and allows for measurements stretched over a relatively long time [36]. The methods are also used extensively in studies of low level sensory processing as well as in cognitive science to study the neural underpinnings of such aspects of cognitive function as attention, memory, perception, and emotions.

In auditory neuroscience and audiology, the basic tools for research are event related potentials (ERPs, extracted from
EEG signals), and event related fields (ERFs, extracted from MEG signals). They represent the neural activity synchronous with short stimuli repeatedly presented to the subject. A vast literature is available on this topic, including information about ERP and ERF components that can be elicited by acoustic stimulation, their dependency on stimulus parameters and state of the subject (e.g. amplitude of some components increase with stimulus loudness as well as with attention), as well as their relevance for assessing auditory pathway function [37-39]. Thus ERPs and ERFs, through utilization of these known signal features, may find a broad spectrum of applications in auditory science.

They have been proposed, for example, as a method for objective assessment of hearing thresholds, supplementary to subjective (tonal audiometry) and auditory brainstembased methods [40]. ERPs and ERFs can gauge various aspects of auditory cortex functioning, allowing changes caused by hearing impairment to be assessed and even assisting with the prediction of outcomes of medical interventions. Examples include studies of the effects of unilateral hearing loss (e.g. altered response lateralisation) $[41,42]$ or development of cortex in congenitally deaf children fitted with cochlear implants $[43,44]$. Higher cognitive functions can also be studied with appropriate ERP/ ERF experimental protocols. The mismatch negativity ERP component is, for example, widely used in experimental settings to assess a subject's ability to discriminate between stimuli differing in say frequency or intensity [45]. It is extensively used in studies focused on language and language development [46]. Even processes such as selective attention, necessary for understanding speech with background multi-speaker noise (the cocktail-party problem) [47], can be pinpointed by properly designed ERP- and ERF-based studies $[37,48]$.

Apart from paradigms based on relatively short repetitive stimuli, as described above, another branch of scientific inquiry is being developed for MEG and EEG. It is organized around using continuous auditory stimulation, either with artificial or natural stimuli (e.g. modulated continuous tones or ongoing speech). Continuous auditory stimulation allows the researcher to not only probe different aspects of neural processing, but also to optimize some aspects of the experimental design (such as making it easier to keep the subject's attention). An example of such an approach is auditory steady-state response (ASSR) measurements - an interesting alternative to hearing threshold assessment $[49,50]$. Another example, highlighting technical possibilities opened up by continuous stimulation, is the frequency tagging technique, where two distinct acoustic signals - differing in frequency of amplitude modulation - are delivered to each ear. One can then study the differences in hemispheric routing of information derived from unilateral stimulation or from binaural interaction [51]. Methods based on continuous stimuli have made it more feasible to study neural encoding of the binaural cues used for sound source localisation, such as interaural time differences (ITDs) [52]. The option of using continuous natural stimuli like music or speech is an important asset. It has been reported that aspects of neural speech encoding and processing, such as comprehension, can be observed in EEG signals [53]. There have been recent applications in assessing certain patient populations, such as users of 
hearing aids or cochlear implants [54,55]. Methodologies based on natural and continuous stimuli can also be used to study lower levels of the auditory system and be performed virtually with the same setting [56].

EEG and MEG signals unrelated to any direct stimulus - i.e. during the resting state, with no task - can also be applied to study audiologically relevant populations. There are reports on patients with tinnitus which tie the condition to specific changes in the EEG signal acquired during the resting state $[57,58]$. A similar approach can be found in studies of children with auditory processing disorders [59]. Some of these findings could be useful as a basis for neurofeedback therapies - where patients train to regulate their brain activity based on chosen markers. Resting state activity patterns collected from a healthy population provide targets for individual training schemes [60,61].

\section{Functional magnetic resonance imaging (fMRI)}

\section{Principles of the method and technical parameters}

MRI (magnetic resonance imaging) measures the absorption of radiofrequency electromagnetic waves by hydrogen nuclei (in water) in a strong magnetic field. In this way MR images are created that show a cross-section of the human body. The method is optimal for studying soft tissue containing high amounts of water, such as the brain. The functional MRI (fMRI) technique depends upon the magnetic properties of oxygenated and deoxygenated blood in the brain, called the blood oxygenation level dependent (BOLD) signal, as a source of contrast in the image. Both anatomical brain images using MR, and functional brain images using $\mathrm{fMRI}$, are acquired using the same device - an MR scanner. During an fMRI exam, the subject lies in the MR scanner and is asked to perform a task (e.g. seeing a picture). The local flow of oxygenated blood increases in activated regions of the brain, an effect called the hemodynamic response (HRF). The onset of a canonical (i.e. typical) hemodynamic response is delayed by approximately $2 \mathrm{sec}$ onds after the stimulus onset, and after about 6 seconds it reaches a plateau. The exact time course of the HRF depends, however, on the brain region where the neuronal processing of the stimulus takes place [62]. When the stimulus ends, the BOLD signal decays within several seconds, crosses the baseline, and stabilizes at least 20 seconds later (Figure 3). In a typical study, it is the difference in BOLD signal between the experimental and control (for example, rest) tasks that is measured [63].

In an fMRI study the field of view (FOV) covers the whole brain, and so it is possible to acquire signals from deep brain structures, not only the cortical surface. The fMRI technique provides functional data with the best spatial resolution, as compared to all other techniques presented in this review (in the order of $1-3 \mathrm{~mm}$ ). The time resolution is limited to seconds, mainly due to the duration of the hemodynamic process in blood vessels. Typical research scanners today have induction fields of 3 tesla. In individual studies at ultra-high magnetic fields ( $\geq 7$ tesla), the functional image spatial resolution can be as low as $0.7 \mathrm{~mm}$ (making it possible to resolve brain activity across cortical layers and columns [64]). Usually, high resolution structural scans (MR) are also collected during the same study, typically with $1 \mathrm{~mm}$ resolution (with ultra-high magnetic fields, even $0.5 \mathrm{~mm}$ ). The structural brain images are then coregistered with the acquired functional images in order

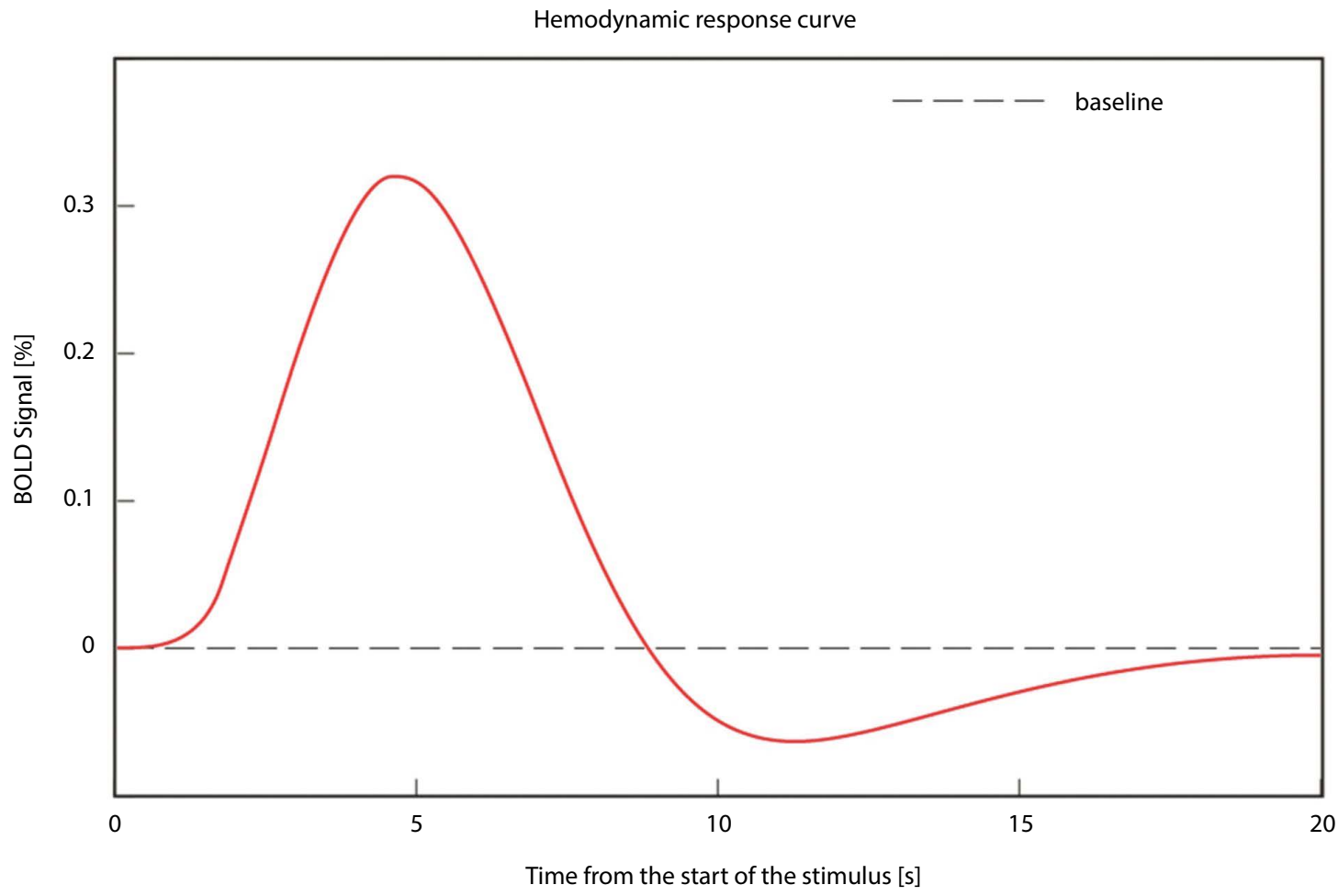

Figure 3. Time trace of the canonical hemodynamic response function (HRF) in the brain. The haemodynamic response allows rapid delivery of blood to active neuronal tissues 
to localise the brain regions involved in a given sensory or cognitive process. $\mathrm{fMRI}$ is non-invasive (no ionizing radiation or contrast agents), is painless, and has no side effects. The method can thus be applied in children and the exam can be repeated numerous times in a row. Furthermore, this neuroimaging method is now relatively widely available. Worldwide, most hospitals that are equipped with an MRI scanner can also apply fMRI procedures. Testing certain cognitive processes, however, requires additional devices such as goggles, headphones, response pads, olfactometers, etc. All these devices have to be MR-compatible, i.e. built from materials that do not interfere with the MR scanner environment. Furthermore, an fMRI experiment is noisy and image quality is sensitive to movement of the participant. In addition, space within the scanner camera is relatively small. The absolute contraindications for an fMRI study include metal objects in the body and claustrophobia; pregnancy and tattoos are relative contraindications [63].

Although current regulations limit the use of ultra-high field scanners $(\geq 7 \mathrm{~T})$ to scientific applications only, their technical development will inevitably lead to clinical application. The first step in this direction has already been taken by one MR scanner manufacturer who has produced a $7 \mathrm{~T}$ scanner approved for both research use and the clinic [65]. The main advantage of ultra-high field scanners is much better signalto-noise ratio (SNR), and thus greater sensitivity to the BOLD effect, which provides increased spatial resolution without losing image quality. As a result, more subtle effects can be detected within a shorter examination time [66].

The main challenge of fMRI studies is the noise produced by the MR scanner during image acquisition, reaching up to $100 \mathrm{~dB}(\mathrm{~A})$. The main source of the acoustic noise, dominating in the range $0.5-2 \mathrm{kHz}$, are the fast-switching gradient coils (electrodynamic forces induce vibrations of the wiring which produces noise) [67-69]. Other sources, producing noise of approx. $70 \mathrm{~dB}(\mathrm{~A})$, are the helium compressor inside the scanner magnet and the air conditioning system [70].

To protect the participant's ears during an fMRI examination, special headphones are always provided to attenuate scanner noise by $20-40 \mathrm{~dB}$. One solution that goes even further is a headphone system with active noise canceling (ANC). Here, advanced signal processors reverse the phase of the acoustic signal coming from the environment and reproduce it in real-time within the headphones, actively attenuating ambient noise. One manufacturer offers this solution.

To minimise the problem of loud acoustic noise during the examination, special "sparse" imaging sequences are also applied. These sequences have salient periods with no noise produced by the gradient coils, during which an auditory task using sounds of lower intensity (i.e. below the standard $60-80 \mathrm{~dB}$ ) can be performed by the participant. This solution is particularly important if the aim of the study is to obtain very precise cortical activation, e.g. related to particular frequency ranges [71-75]. In terms of future developments, so-called "silent" imaging sequences in which the scanner noise intensity is reduced by $95 \%$ have been available since 2012, but they can only be applied to acquire structural images. For functional studies, such imaging sequences are not yet commercially available as they are still in the test phase (more information about acoustic noise reduction can be found in [76]).

In addition to fMRI equipment developments, artificial intelligence (AI) is being used to support signal processing. One example is use of computing power and AI algorithms to decode brain activity in real-time, such as in neurofeedback where precise autoregulation of brain function is the goal $[77,78]$.

\section{General applications and applications in auditory research}

The 21 st century has seen a great increase in fMRI use in various fields of medicine and research. At many centers worldwide, fMRI is the method of choice when assessing various surgical approaches and risks prior to serious neurosurgical procedures. Increasingly, fMRI is being used to monitor treatment outcomes, the effectiveness of pharmacological drugs, and brain plasticity. fMRI is also becoming a useful tool in neuropsychology and psychiatry to study the neural underpinnings of perception, attention, memory, motivation, and cognition [79].

In the research domain, the number of fMRI studies continues to increase, along with the list of potential applications. fMRI can be applied to study functioning of all senses (vision, audition, touch) [80] and virtually any cognitive process, social behavior, emotions, reaction to unexpected events, stress, and brain hemisphere lateralization. One advantage of fMRI is its relatively high sensitivity and specificity for detecting brain activation areas related to the performance of a particular task. Repeated measurements of dynamic processes in the brain, such as the effects of rehabilitation or training, are also possible.

fMRI studies of the auditory system have been reviewed in several papers [81-83]. The main applications of fMRI in auditory research include: analysis of acoustic stimuli of various complexity, language processing (phonology, syntax,

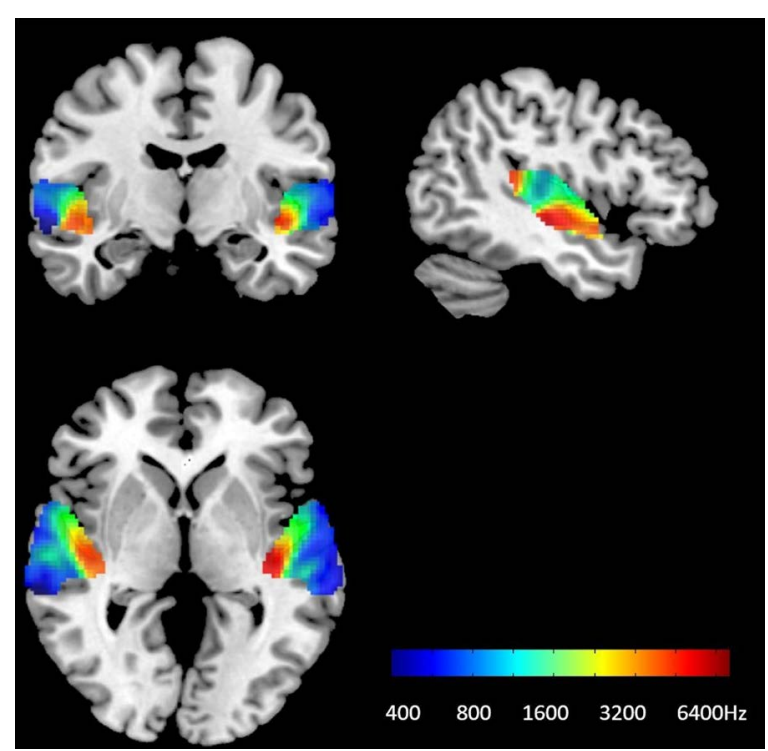

Figure 4. Tonotopic organisation of the auditory cortex in the brain. The colors indicate the regions with the highest activation in response to a given frequency of stimulation 
semantics) [84-86], speech production, memory and auditory imagery, reading, auditory cortex function in patients with selective hearing deficits (partial deafness), influence of noise and high-intensity sounds on auditory cortex activation, and brain functional asymmetry for speech. One example of a spectacular use of the fMRI technique is to gauge the tonotopic organisation of the auditory cortex (Figure 4). The frequency-specific organisation of the cortex has been shown to exactly mirror sound frequency encoding in the cochlea [69-75,87-90]. In several studies using ultra-high field (7 T) fMRI and cortical depth analysis techniques, the auditory cortex was sampled with $1 \mathrm{~mm}$ isotropic voxels and it was found that the tonotopic organisation is in fact more consistent across individuals than previously thought [91]. The temporal resolution of $\mathrm{fMRI}$ (even ultra-fast $\mathrm{fMRI}<1 \mathrm{~s}$ ) is too low to follow, in real-time, neuronal oscillations related to complex sounds such as speech, but it is possible to reconstruct the sequence of simple tones that a person has been listening to over a period of time [92,93].

An alternative to task-based fMRI is resting-state fMRI which measures low-frequency spontaneous fluctuations of BOLD signals in the brain when no task is being performed [94]. Resting-state brain activity has been evaluated in clinical populations, including patients with central auditory processing disorders but preserved peripheral hearing [95], and in sensorineural hearing loss (partial deafness), suggesting alterations probably related to the experienced sensory deprivation [96-98]. By taking an fMRI scan before cochlear implantation, it has been suggested that specific patterns of brain activation are good predictors of the patient's performance after surgery $[99,100]$, although these findings need to be confirmed. Metal components in a cochlear implant is a contraindication for fMRI use, preventing assessment of how the auditory input delivered by an implant is processed. To do this, other techniques described in this review are recommended. Structural MR brain evaluation is possible in patients with a CI, but the implant still generates image artefacts [101,102].

\section{Functional near-infrared spectroscopy (fNIRS)}

\section{Principles of the method and technical parameters}

Spectroscopy is the study of the interaction between matter and electromagnetic radiation, involving either absorption, emission, or scattering [103]. Functional near-infrared spectroscopy is also a spectroscopic technique, as it is based on the analysis of absorption of nearinfrared light (between $650-950 \mathrm{~nm}$ ) by hemoglobin $[104,105]$. The fact that oxygenated ( $\mathrm{HbO} 2)$ and deoxygenated (HbR) hemoglobin have different optical properties allows one to indirectly infer the neural activity of a given brain region whose blood flow is examined using fNIRS, similar to the fMRI technique.

When a brain area is active and involved in executing a certain task, the brain's metabolic demand for oxygen and glucose increases, leading to an oversupply of regional cerebral blood flow (CBF) [106]. This oversupply produces an increase in $\mathrm{HbO} 2$ and a decrease in $\mathrm{HbR}$ concentrations; these are estimated by changes in near-infrared light absorption that can be measured by fNIRS. In particular, $\mathrm{HbO} 2$ and $\mathrm{HbR}$ absorb NIR light differently: $\mathrm{HbO} 2$ absorption is higher for wavelengths $>800 \mathrm{~nm}$, while HbR absorption is higher for wavelengths $<800 \mathrm{~nm}$ [107].

A feature enabling the use of fNIRS for non-invasive measurement of $\mathrm{HbO} 2$ and $\mathrm{HbR}$ level changes in the human brain is the permeability of NIR light through the scalp and skull. This phenomenon was first described in 1977 by Jobsis [108].

Measurements using fNIRS are made with a set of optodes, including light sources and light detectors [109], as shown in Figure 5. Light sources emit NIR light from LEDs or LDs (laser diodes), while detectors collect the back-scattered light and measure changes in light level. Since absorption within the NIR optical window (the range of wavelengths where NIR light has its maximum depth of penetration in tissue) is mainly due to $\mathrm{HbO} 2$ and $\mathrm{HbR}$, changes in light attenuation at a given wavelength can be expressed as a linear combination of concentration changes of $\mathrm{HbO} 2$ and HbR. Most of the commercially available systems, known as continuous-wave (CW) fNIRS instruments, use continuously emitted NIR light, typically at 2 or 3 wavelengths. They measure light attenuation due to tissue scattering and absorption by estimating the ratio of the output light intensity to the input light intensity. By subtracting the first attenuation measurement from the following attenuation measurements, changes in attenuation are estimated and used to derive changes in concentrations of $\mathrm{HbO} 2$ and $\mathrm{HbR}$.

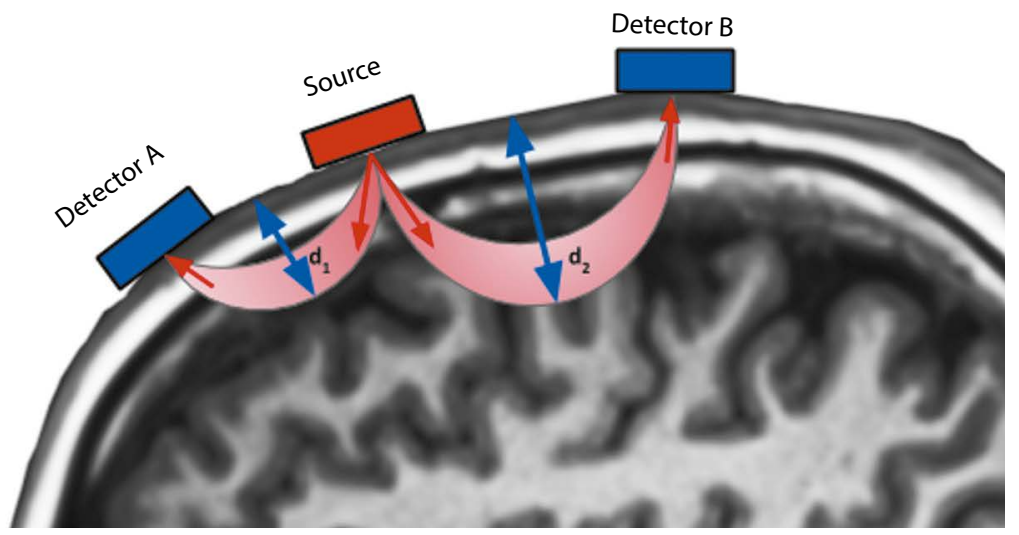

Figure 5. Path (shown in pink) of the NIR light from the light source (red) to the detectors (blue) through the different layers of the head. The penetration depth of the light is proportional to the source-detector distance $\left(d_{1}\right.$ : superficial channel; $d_{2}$ : deeper channel). The MRI image comes from our own data 
The temporal sampling rate of fNIRS devices ranges from $1 \mathrm{~Hz}$ up to $250 \mathrm{~Hz}$, depending on the manufacturer [109]. The signal measured with fNIRS, however, is based on the relatively slow hemodynamic response. Therefore, the effective temporal resolution in terms of the time course of neural activity is lower, and similar to the fMRI technique $(1-3 \mathrm{~s})[110,111]$. The spatial resolution in fNIRS depends on the density of sources and detectors: the higher the density of optodes, the higher the resolution [112]. However, there is a factor limiting the spatial resolution in fNIRS. The spacing between the source and the detector must be large enough to obtain significant sensitivity to the signal originating in the brain tissue (and not from the superficial layers such as the skull or skin). Increasing the source-detector distance results in deeper light penetration (see Figure 5); but a larger source-detector distance requires higher optical power from the source in order to maintain a similar SNR. Otherwise, less light is received by the detector, since light is absorbed along the way. The optical power used in fNIRS is limited by the risk of tissue heating.

Taking all these factors into consideration, most fNIRS studies are conducted using sources and detectors arranged in a sparse grid. Typical values that ensure depth sensitivity and the SNR trade-off are source-detector separations of $30-35 \mathrm{~mm}$ for studies in adult participants and 20-25 $\mathrm{mm}$ for infants [107], resulting in an effective spatial resolution of $1-2 \mathrm{~cm} \mathrm{[113]} \mathrm{and} \mathrm{a} \mathrm{head} \mathrm{penetration}$ depth of $2-3 \mathrm{~cm} \mathrm{[114].}$

Recently, the development of high-density diffuse optical tomography (HD-DOT) instrumentation has dramatically improved spatial resolution (to below $1 \mathrm{~cm}$ ) and brain specificity of optical neuroimaging $[113,115,116]$. Through utilizing a densely overlapping array of sources and detectors, it is possible to make multiple measurements within each voxel of the imaged volume [117], but the penalty is a higher cost system. Additionally, due to the larger number of channels ( 96 sources and 92 detectors in [118]), HD-DOT has a larger field of view than traditional fNIRS systems, enabling investigation of multiple brain areas simultaneously.

The main disadvantage of the fNIRS technique is a lack of standardized optode configuration, leading to problems with accuracy and reproducibility of results. In addition, the anatomical source of neural activity has to be inferred by other means, such as a structural image from an MRI, or registering sensor positions using a 3D scanner [119]. Another disadvantage is the ability to image only the superficial cortex in the limited FOV (full-brain fNIRS is not yet available). The SNR in fNIRS depends on good light coupling (transfer of light) between source and detector, so factors such as hair color and density, and skin pigmentation, can have a tremendous impact on signal quality [120].

In the future, fiberless designs that place all the electronics on the head have the potential to dramatically increase the wearability and portability of fNIRS systems [121]. Further advances in reliable and efficient functional-to-anatomical co-registration methods (such as with MR images) are also highly sought after. As with all neuroimaging methods, imaging instrumentation is becoming increasingly sophisticated and fNIRS imaging of the brain will eventually provide improved spatial resolution. This will enable further progress in data analysis algorithms and enhance the range of applications.

\section{General applications and applications in auditory research}

fNIRS has found application in the clinic in the detection of central nervous system bleeding and perinatal leukomalacia (white matter degeneration) in prematurely born babies. Using ultrasound examination this condition is seen only at about 3-4 weeks of age, while with fNIRS it can be detected much earlier [122]. Collecting measurements during free movement makes it possible to use fNIRS during neurorehabilitation [123].

In auditory neuroscience, fNIRS is gaining popularity due to features such as silent data acquisition, a more ecological experimental environment (i.e. undertaken in conditions closer to the subject's everyday experience) [124], no interference from electromagnetic bionic devices such as cochlear implants [125], and a signal that is relatively motion-insensitive. Because of these advantages, researchers are seeing the potential of fNIRS in auditory research for both normal-hearing populations and those with auditory dysfunctions [126]. Especially in demanding clinical populations such as small children with a CI or the elderly with a hearing aid, fNIRS may be the method of choice in experiments focused on brain regions involved in auditory processing.

In the normal-hearing population, fNIRS has been used to evaluate the hierarchical organization of speech processing [113] using a HD-DOT system that covers $~ 50 \%$ of the head surface [127], music perception [128], sound discrimination [129-131], speech production [132], and effortful listening to normal and degraded speech [133]. Due to fNIRS's advantages, such as immunity to movement and portability, it has been applied in a number of studies of auditory-related function in infants and children, such as speech perception [134], comprehension, and prosody [135].

fNIRS research in young cochlear implant (CI) recipients has thus far focused on the reliable detection of hemodynamic responses to speech [125]. Other studies have been conducted in adults with CIs examining brain-behavior correlates of speech perception skills [136], speech processing in different acoustic conditions [137], cross-modal reorganization of the brain (e.g. auditory cortex processing of visual stimulation), and multimodal processing - e.g. audio-visual speech $[126,138,139]$ and visual language processing (lip-reading) before and after a CI [140].

In tinnitus patients, fNIRS technology has been used to assess changes in activation of brain areas involved in acoustic noise processing before/after rTMS (transcranial magnetic stimulation) treatment [109], or to assess resting-state functional connectivity (RSFC) in comparison with normal-hearing subjects [141]. 


\section{Positron emission tomography (PET)}

\section{Principles of the method and technical parameters}

Positron emission tomography (PET) is the most advanced functional imaging technique in nuclear medicine [142]. It allows for in vivo measurements of biochemical processes in body tissue by administering a radioactive compound to the blood flow (or airflow) of the subject. Due to limited spatial resolution, PET is complementary to structural imaging methods such as MR or CT.

Setting up a study (Figure 6, steps 1-8) requires advanced equipment and preparation, as well as systematic quality control. First, a batch of isotopes is produced in a cyclotron, a type of particle accelerator (step 1). The four basic $\mathrm{PET}$ radioisotopes that can be used for PET imaging are ${ }^{11} \mathrm{C},{ }^{15} \mathrm{O},{ }^{13} \mathrm{~N}$, and ${ }^{18} \mathrm{~F}$, all with a half-life (the time for half the atoms of a radioactive substance to disintegrate) spanning between 2 min and several hours. For production of oxygen-15 (half-life of $2 \mathrm{~min}$ ), the cyclotron has to be available on-site. In the next step the isotope is chemically combined with a biological carrier, such as water or glucose, in special isolated cells (step 2). The compound produced is called a radiopharmaceutical or radiotracer. There are dozens of radiopharmaceuticals available today, each targeted at measuring a specific biological process. The most common is fluorine-18 combined with glucose [F18 FDG], mostly used for whole-body PET scans of oncology patients [143].

The synthesized radiopharmaceutical, after quality control for parameters such as biological and chemical purity and level of radiation, is delivered via injection or inhalation to the subject, who is placed in a PET scanner (steps 3 and 4). Following injection into body tissue, the radioisotope decays and emits positrons. After travelling a short distance, the positrons encounter electrons already present in tissue, which leads to a phenomenon called an annihilation event (step 5). Annihilation produces two gamma ray photons moving in opposite directions, and these can be picked up by detectors placed in a ring of the PET camera surrounding the subject. Only photons detected by two diametrically opposite detectors (in a line of response, LOR) within a certain time window (6-12 ns) and with a certain energy (approx. $511 \mathrm{keV}$ ) are considered "true events" and are used for image reconstruction. A series of two-dimensional images collected from a certain body part is used to reconstruct $3 \mathrm{D}$ images of the isotope distribution. The effective temporal resolution of a PET image is between several seconds and several minutes, with an effective spatial resolution of 3-5 cm [144]. Both these parameters depend on the intrinsic timing of the measured physiological events, as well as features such as the dead time of the PET detectors [83]. These days PET images are almost always coregistered (integrated) with high-spatial-resolution images acquired in the same person with the use of computed tomography in the same PET-CT device. Another alternative is to combine a PET image with structural MR data collected in a separate device or in the same multimodal PET-MR device.

\section{General applications and applications in auditory research}

The PET technique is mostly used in whole-body oncology. Nevertheless, it has also found its way into other areas of medicine, such as neurology and psychiatry [145]. Research on cognitive and sensory processes, i.e. cognitive brain imaging, comprises only a tiny percentage of PET applications. Here two radiotracers have commonly been used: F18 coupled with glucose [F18 FDG] and $\mathrm{O} 15$ coupled with water $[\mathrm{O} 15 \mathrm{H} 2 \mathrm{O}]$. These two are used to measure regional metabolism (glucose) or blood flow (water) corresponding to the involvement of a certain brain region in the tested cognitive task. Indeed, tight coupling has been shown between local energy consumption and neuronal function. The earliest studies

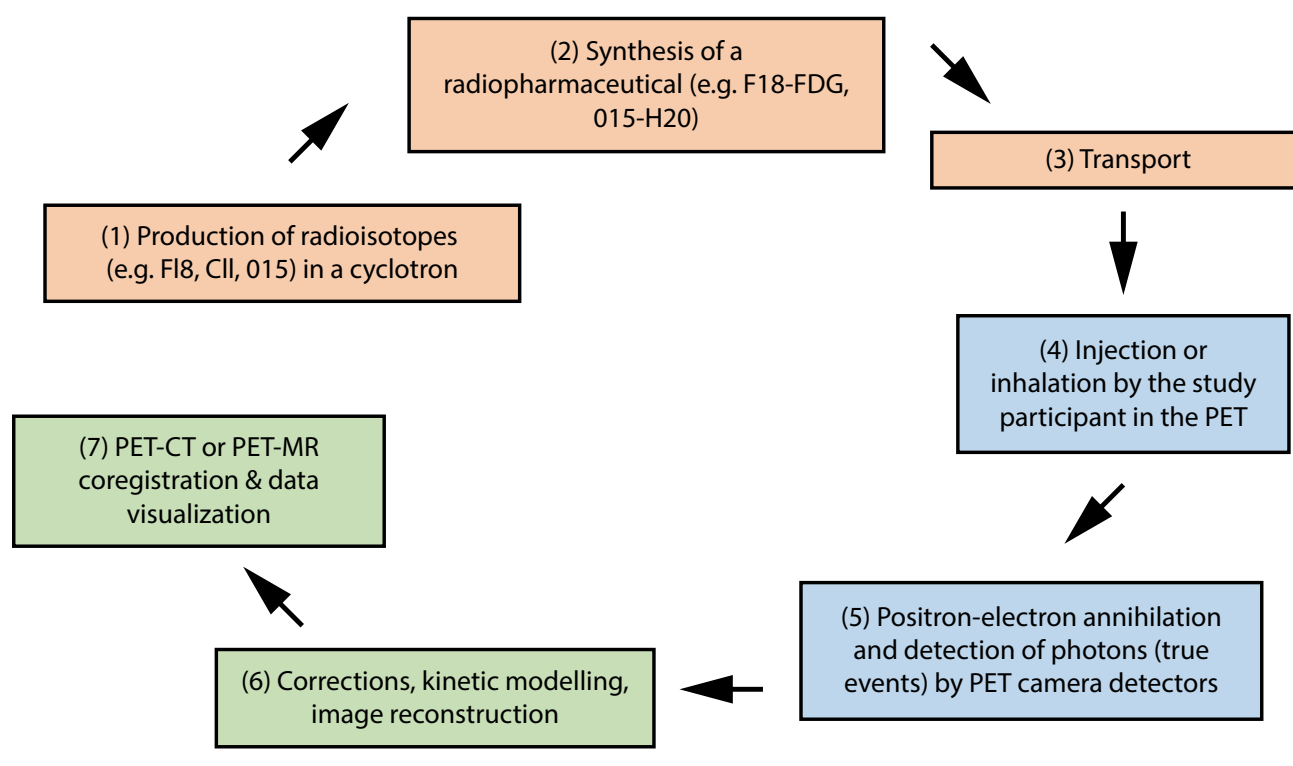

Figure 6. Sequential steps in a typical functional brain PET study. The three phases are distinguished by different colors: technical preparation (orange), data collection (blue), and data analysis (green) 
applying PET in this field were published in the 1980s [144]. O15 is a freely diffusible radioisotope with a very short half-life $(2 \mathrm{~min})$ which allows multiple repetitions of the study conditions in order to increase signal-to-noise ratio. Therefore, a typical study consists of several experimental runs every 7 to 10 minutes - the estimated time of a complete wash-out of $\mathrm{O} 15$ before the next injection and measurement. This radiopharmaceutical has been mainly used for brain studies involving task performance. With 18F-FDG PET, the radiopharmaceutical has a halflife of $2 \mathrm{~h}$ and thus the subject needs to wait for approximately an hour after injection until image acquisition can begin [146]. This method is therefore mainly used for resting-state brain studies. For both these measures, the typical PET dose is very small (for the brain, significantly smaller than one year's exposure to natural background radiation) and is strictly controlled.

The PET technique has also been used for several decades to access the central auditory system [147]. The main argument in favour of this method is the relative silence during data acquisition, as opposed to loud fMRI scanning (especially true in the 1980s and '90s, when there were no quiet sequences yet available for fMRI data acquisition - see references below). The argument for using PET instead of fMRI still stands with respect to evaluation of cortical plasticity in patients using auditory devices, including hearing aids and cochlear implants. The use of fMRI in these patients is problematic due to the electromagnetic artefacts generated by speech processors. This is true despite the fact that today several CI devices are compatible with 3T MR: nevertheless the devices only allow imaging of brain anatomy (and not function) and the implant itself still induces considerable image artefacts. CI systems that are not compatible with MR systems cannot be placed in a scanner, as there is a danger of the magnet heating up or being pulled from the body [101].

PET imaging has been used to study a wide number of auditory processes and populations. Several works employing multiple brain-blood flow measurements (O15-H2O PET) have focused on central auditory processing in normal hearing, such as language networks $[148,149]$, the role of the cerebellum in passive listening and pitch discrimination [150], or music appraisal [151]. In one study researchers even applied PET to assess the tonotopic organization of the auditory cortex (despite the limited spatial resolution of PET images) [152] and showed functional patterns which have now been confirmed with a number of fMRI experiments. Since a cochlear implant is not a contraindication for PET, many works have been published in patients using CIs [153]. Cortical processing has been evaluated in response to various types of auditory stimuli, including speech [149,154-166], audio-visual speech [162,167], music [156], and noise [157-160,162,168]. In a unique effort, a team led by Berding used PET on patients with an auditory implant and/or a midbrain implant who listened to auditory tones and speech, showing the potential of this imaging method to assess the integrity of several levels of the auditory system [154]. In all these works, the main tested questions involved laterality of the cortical auditory responses depending on the type of stimulation (e.g. speech vs noise) and/or the side of the implant, as well as the effects of cross-modal plasticity (e.g. whether auditory stimulation would evoke responses in sensory cortices specialising in other modalities, such as the visual or sensorimotor cortex $[155,163,169]$. Several O15-H2O PET studies have found correlations between the intensity or size of regional activations before cochlear implantation and speech comprehension after cochlear implantation $[99,157,165,168,170]$, suggesting that PET findings might have some predictive power. Thus far only a few studies have measured central auditory processing in CI users longitudinally $[161,163]$, a fact related to the limited availability, cost, and invasiveness of this neuroimaging method.

As mentioned, most F18-FDG PET studies focus on in vivo resting-state metabolism in the brain, i.e. with no stimuli presented or explicit task. Auditory studies have here focused on patients with tinnitus - a condition in which there is the perception of sound but with no external acoustic input. Several studies have shown an increase in resting metabolism in the auditory cortices of patients with tinnitus [171-173] - with several exceptions such as in [174]. One of these works showed a correlation between resting state metabolism in certain brain regions and features of tinnitus such as duration, laterality, and level of distress [173]. Resting-state brain glucose metabolism has also been evaluated pre-operatively in CI candidates [175-177] as well as in actual CI users [170,178-180], indicating altered information processing mechanisms in the cerebral networks of these patients, often including the auditory cortices.

In another application of F18-FDG-PET, listening to speech often showed specific cortical processing in postlingual CI users $[159,166,181]$, with patterns closer to normal when the patients were users of two, instead of one, CI [164,181]. Few research groups have applied PET imaging to evaluate the cortical responses of children who were born deaf, comparing before CI [179,182] and after CI responses [183]. During the exam, the children were either resting [179] or listening to speech [182] or audio-visual speech [183]. PET has not been extensively applied to pediatric populations because of the risks associated with exposure to radioactivity.

In conclusion, although PET is a unique neuroimaging method, it can no longer compete with fMRI for assessment of cortical auditory processing. There are now fMRI sequences available that significantly limit scanner noise. The main caveat of PET is the ionizing radiation that is delivered to the participant, as well as related costs. However, the method remains one that can be applied for functional brain imaging in special populations of patients who have various kinds of magnetic implants, including hearing devices. PET is also the only method that allows for in vivo imaging of processes happening at a molecular level. In terms of future developments, new PET studies of neurotransmission in healthy and diseased brains continue to appear. In addition, there are advances in the engineering design of PET imaging systems, including further development of the detector crystals and of mathematical methods for image reconstruction. At this time, however, the application of PET specifically for auditory research is questionable, unless combined with other neuroimaging methods (see below). 


\section{Discussion}

\section{Comparative summary of techniques}

In this work we have reviewed five neuroimaging methods which have found application in auditory research focused on cortical processing. In order to highlight the most important information described in previous sections, a comparison between the methods is provided in Table 1, which might prove helpful in summarising new knowledge or allowing a researcher to choose the most appropriate method for their own auditory experiments. The values in the table refer to parameters achieved by typical systems used in laboratories or clinics. It has to be kept in mind, however, that better parameters than those given in the table can be achieved by using more sophisticated methods, but usually at much higher cost (see discussion of $7 \mathrm{~T}$ scanners in the fMRI section).

As shown in Table 1, each method poses specific challenges in terms of preparation, data acquisition, and data analysis. Each method also has its strengths and weaknesses, which makes it more or less capable of answering a given research question.

First of all, as already mentioned, certain methods presented in this article are based on different representations of physiological processes related to cortical auditory processing (e.g. blood hemodynamics vs components of neural activity), which in turn determine the parameters of the measurement, such as temporal resolution. In general, methods that measure brain hemodynamics - fMRI and fNIRS - have poorer effective temporal resolution (1-3 s), due to the delay of blood flow changes following neuronal responses, than do methods sampling neural activity in a more direct way (EEG/MEG $\sim 1 \mathrm{~ms}$ ). Temporal characteristics of MEG and EEG make it possible to track neural processes like speech processing in real time, suggesting they are promising tools for future speech therapies and training monitored by neural recordings.

Furthermore, the same cortical process can be measured using different techniques. As an example, brain hemodynamics can be studied using either fMRI or fNIRS. The fMRI method utilizes a set of radiofrequency transmitters and receivers placed in a high magnetic field. The measurements of the signal in the whole brain volume are of exceptional spatial resolution. However, in fMRI the study environment is not ecological, as participants have to lie down and be still inside the rather narrow bore of an MRI scanner. The device is also intrinsically loud. In comparison, fNIRS utilizes a set of light sources and detectors placed directly on the head. Such a setup is quiet, is mobile or quasi-mobile, is feasible for small children, and has a high sensitivity to hemodynamic effects if properly fitted. The spatial resolution is, however, inferior to fMRI and is limited to superficial layers of the cortex. In sum, the specific study environment for fMRI may be a major limitation for some auditory experiments, such as those requiring sounds presented in a $3 \mathrm{D}$ space or the participation of small children. In such cases, the use of fNIRS is preferable. At the same time, in adults fMRI is often the method of choice in studies focusing on precise brain localisation of auditory-related processes.

When comparing the effective spatial resolution of the methods, it should be kept in mind that only in PET and fMRI is the spatial resolution defined for the whole brain, in contrast to EEG, MEG, and fNIRS, where the effective resolution is well defined only for the superficial layers.

Table 1. Comparison of the discussed neuroimaging techniques

\begin{tabular}{|c|c|c|c|c|c|}
\hline & PET & fMRI & EEG & MEG & fNIRS \\
\hline Evaluated process & biochemical & hemodynamic & bioelectrical & biomagnetic & hemodynamic \\
\hline Source of the signal & brain volume & brain volume & head surface & head surface & head surface \\
\hline Effective spatial resolution & $3-5 \mathrm{~mm}$ & $\begin{array}{c}1-2 \mathrm{~mm}, \\
{[<1 \mathrm{~mm} \text { for } 7 \mathrm{~T}]}\end{array}$ & $20-50 \mathrm{~mm}$ & $10-50 \mathrm{~mm}$ & $\begin{array}{l}10-20 \mathrm{~mm} \\
{[<10 \mathrm{~mm} \text { for }} \\
\text { HD-DOT] }\end{array}$ \\
\hline $\begin{array}{l}\text { Effective temporal } \\
\text { resolution }\end{array}$ & $\sim 1-2 \mathrm{~min}$ & $1-3 s$ & $\sim 1 \mathrm{~ms}$ & $\sim 1 \mathrm{~ms}$ & $1-3 s$ \\
\hline Sensitivity to movement & medium & high & medium & high & medium/low \\
\hline $\begin{array}{l}\text { Coregistration with } \\
\text { anatomical data }\end{array}$ & always & always & possible & possible & possible \\
\hline $\begin{array}{l}\text { Ecological test } \\
\text { environment }\end{array}$ & no & no & yes & no & yes \\
\hline Portability & no & no & yes & no & yes \\
\hline General contraindications & $\begin{array}{c}\text { yes: } \\
\text { children; } \\
\text { pregnancy }\end{array}$ & $\begin{array}{l}\text { yes: metals or } \\
\text { electronic devices } \\
\text { inside the body, } \\
\text { claustrophobia }\end{array}$ & no & no & no \\
\hline Silent technique & yes & no & yes & yes & yes \\
\hline $\begin{array}{l}\text { Compatibility with auditory } \\
\text { devices }\end{array}$ & yes & no & $\begin{array}{l}\text { yes (but creates } \\
\text { artifacts) }\end{array}$ & $\begin{array}{l}\text { yes (but creates } \\
\text { artifacts) }\end{array}$ & yes \\
\hline Cost of equipment & $\sim 2 \mathrm{M}$ Euro & $\sim 2$ M Euro & $<0.25 \mathrm{M}$ Euro & $>2$ M Euro & $<0.25 \mathrm{M}$ Euro \\
\hline
\end{tabular}


Additionally, the methods presented in this article differ in the degree of portability and/or sensitivity to movement - factors that are crucial in studies of non-cooperating subjects, such as small active children or the elderly. fNIRS is the method least sensitive to motion artefacts and so is employed in studies where the participant can freely move. In terms of portability, EEG and fNIRS are also available in portable versions. However, fMRI image quality (especially in $7 \mathrm{~T}$ scanners) is significantly affected by movement, caused by pulsating blood vessels, muscle vibration, and involuntary movement. Therefore, it is suitable only for experiments that can be performed in an immobile supine position.

From among the techniques considered, auditory implants and hearing aids are a contraindication only for the fMRI technique, an important factor when planning a study of hearing-impaired populations. In other methods, such as EEG/MEG, electronic device artifacts can be detected and removed or minimised. PET (in combination with CT) and fNIRS are the methods least affected by such devices.

\section{Multimodal imaging}

Multimodal imaging, i.e. probing one neural process with more than one imaging technique (in simultaneous or sequential sessions), is gaining in popularity and has already found a place in some fields of medicine [184]. Examples of functional multimodal imaging in auditory research include EEG-fMRI, PET-EEG, EEG-MEG, and fNIRS-EEG. Putze et al. used combined fNIRS and EEG signals in a human-computer interface that detected modality-specific (auditory vs visual) perception with up to $94.8 \%$ classification accuracy [185]. In an example of PET-EEG, correlations were established between the loudness dependence of auditory evoked potentials and serotonin levels in the midbrain and in auditory cortex (temporal lobe) [186]. One MEG-EEG study showed that, under certain conditions, modelling of sources underlying auditory evoked responses benefits from combining both techniques, with MEG providing a good starting point and EEG allowing the results to be refined so that activity not detected by MEG can be modelled as well [187].

However, in studies of sensory and cognitive processes the most common approach has been to combine EEG and $\mathrm{fMRI}$, providing data with both high temporal (EEG) and spatial (fMRI) resolution [188]. EEG allows one to closely follow the temporal dynamics, whereas fMRI can indicate where exactly in the brain a process is happening. A sequential EEG-fMRI study during an auditory oddball task showed fMRI activations that were modulated together with the amplitude of the P300 component of event related potentials, allowing better localisation of the underlying P300 generators [189]. Although EEG-fMRI is now quite popular in other fields of research, up to date only a few truly simultaneous (not sequential) ERP-fMRI studies have focused on auditory processing (sound frequency discrimination) [190,191]. In Poland, the Institute of Physiology and Pathology of Hearing in Warsaw was the first to apply simultaneous EEG-fMRI registration to study attention and auditory processing in children [192] and adults [193].

Multimodal neuroimaging requires very careful planning of the study paradigms - specific for each method - and advanced data analysis, including removal of artefacts (for simultaneous data acquisition) as well as image fusion algorithms. Nevertheless, it can help better comprehend brain activity and the causality of neuronal events, and thus will most probably develop further, both for auditory research and clinical applications [194,195].

\section{Conclusion}

In this review we have surveyed several neuroimaging methods that can be applied to study auditory processing in the brain. We described their technical and physiological backgrounds in order to provide the reader with a basic understanding of the measurement system, supported by a set of references for in-depth reading. For each method, a variety of cases have been presented, illustrating the specific features and advantages of each technique for auditory research. Finally, we took up the topic of multimodal imaging in which the specific advantages of the methods are combined in order to provide more detailed information about the auditory process of interest. While reviews of functional neuroimaging modalities already exist in the literature, to the best of the authors' knowledge, this is the first review that concentrates specifically on auditory research and compares all four techniques. We therefore hope this work will prove useful for researchers beginning studies in auditory neuroscience as well as all those interested in extending their knowledge about neuroimaging techniques and applications.

\section{References}

1. Moore BCJ. An Introduction to the Psychology of Hearing. London: Academic Press; 2003.

2. Hall JW, Swanepoel DW. Objective Assessment of Hearing. Plural Publishing; 2009

3. Burkard RF, Eggermont JJ, Don M, editors. Auditory evoked potentials: basic principles and clinical application. Philadelphia: Lippincott Williams \& Wilkins; 2007.

4. Kochanek KM, Śliwa L, Gołębiowski M, Piłka A, Skarżyński H. Comparison of $3 \mathrm{ABR}$ methods for diagnosis of retrocochlear hearing impairment. Med Sci Monit, 2015 Dec 7; 21: 3814-24.

5. Hämäläinen $M$, Hari R, Ilmoniemi RJ, Knuutila J, Lounasmaa OV. Magnetoencephalography: theory, instrumentation, and applications to noninvasive studies of the working human brain. Rev Mod Phys, 1993 Apr 1; 65: 413-97.
6. Hari R, Puce A. MEG-EEG Primer. Oxford, New York: Oxford University Press; 2017.

7. Olejniczak P. Neurophysiologic basis of EEG. J Clin Neurophysiol, 2006 Jun; 23: 186-9.

8. Im C, Seo J-M. A review of electrodes for the electrical brain signal recording. Biomed Eng Lett, 2016 Aug; 6: 104-12.

9. Puce A, Hämäläinen M. A review of issues related to data acquisition and analysis in EEG/MEG studies. Brain Sci, 2017 May 31; 7(6): 58 .

10. Klass DW. The continuing challenge of artifacts in the EEG. Am J EEG Technol, 1995 Dec; 35: 239-69.

11. Sun L, Hämäläinen M, Yoshiookada. Noise cancellation for a whole-head magnetometer-based MEG system in hospital environment. Biomed Phys Eng Express, 2018 Aug 7; 4(5):055014. 
12. Cohen D, Cuffin BN. Demonstration of useful differences between magnetoencephalogram and electroencephalogram. Electroencephalogr Clin Neurophysiol, 1983 Jul; 56: 38-51.

13. Hari R, Parkkonen L. The brain timewise: how timing shapes and supports brain function. Philos Trans R Soc B, 2015 May 19; 370:20140170.

14. Cohen MX. Where does EEG come from and what does it mean? Trends Neurosci, 2017 Apr; 40: 208-18.

15. Chu CJ. High density EEG: what do we have to lose? Clin Neurophysiol, 2015 Mar; 126: 433-4.

16. Michel CM. High-resolution EEG. In Handbook of Clinical Neurology. Elsevier; 2019. pp. 185-201.

17. Nurminen J, Taulu S, Nenonen J, Helle L, Simola J, Ahonen A. Improving MEG performance with additional tangential sensors. IEEE Trans Biomed Eng, 2013 Sep; 60: 2559-66.

18. Okada Y, Hämäläinen M, Pratt K, et al. BabyMEG: A wholehead pediatric magnetoencephalography system for human brain development research. Rev Sci Instrum, 2016 Sep 1; 87:094301.

19. Nunez PL, Srinivasan R. Electric Fields of the Brain: The Neurophysics of EEG. 2nd ed. Oxford; New York: Oxford University Press; 2006.

20. Petrov Y, Nador J, Hughes C, Tran S, Yavuzcetin O, Sridhar S. Ultra-dense EEG sampling results in two-fold increase of functional brain information. NeuroImage, 2014 Apr 15; 90: 140-5.

21. Michel CM, Brunet D. EEG Source imaging: a practical review of the analysis steps. Front Neurol, 2019 Apr 4; 10.

22. Wendel K, Väisänen $\mathrm{O}$, Malmivuo J, et al. EEG/MEG source imaging: methods, challenges, and open issues. Comput Intell Neurosci, 2009; 2009:e656092.

23. Hedrich T, Pellegrino G, Kobayashi E, Lina JM, Grova C. Comparison of the spatial resolution of source imaging techniques in high-density EEG and MEG. NeuroImage, 2017 Aug; 157: 531-44.

24. Debener S, Minow F, Emkes R, Gandras K, de Vos M. How about taking a low-cost, small, and wireless EEG for a walk? Psychophysiology, 2012 Sep 26; 49: 1617-21.

25. Hill RM, Boto E, Holmes N, et al. A tool for functional brain imaging with lifespan compliance. Nat Commun, 2019 Nov 5; 10: 1-11.

26. Iivanainen J, Stenroos M, Parkkonen L. Measuring MEG closer to the brain: performance of on-scalp sensor arrays. NeuroImage, 2017 Feb 15; 147: 542-53.

27. Homölle S, Oostenveld R. Using a structured-light 3D scanner to improve EEG source modeling with more accurate electrode positions. J Neurosci Methods, 2019 Oct 1; 326:108378.

28. Rodríguez-Calvache M, Calle A, Valderrama S, López IA, López JD. Analysis of exact electrode positioning systems for multichannel-EEG. Commun Comput Inf Sci, 2018; 523-34.

29. Bleichner MG, Debener S. Concealed, unobtrusive ear-centered EEG acquisition: cEEGrids for transparent EEG. Front Hum Neurosci, 2017 Apr 7; 11: 163.

30. Debener S, Bleichner MG. Transparent electroencephalography?: exploring ear-EEG for long-term, mobile electrophysiology. IEEE Xplore; 2019.

31. Mikkelsen KB, Kappel SL, Mandic DP, Kidmose P. EEG recorded from the ear: characterizing the ear-EEG method. Front Neurosci, 2015 Nov 18; 9: 438.

32. Barkley GL, Baumgartner C. MEG and EEG in epilepsy. J Clin Neurophysiol, 2003 Jun; 20: 163-78.

33. Enriquez-Geppert S, Huster RJ, Herrmann CS. EEG-neurofeedback as a tool to modulate cognition and behavior: a review tutorial. Front Hum Neurosci, 2017 Feb 22; 11.
34. Florin E, Bock E, Baillet S. Targeted reinforcement of neural oscillatory activity with real-time neuroimaging feedback. NeuroImage, 2014 Mar; 88: 54-60.

35. Birbaumer N, Cohen LG. Brain-computer interfaces: communication and restoration of movement in paralysis. J Physiol, 2007 Mar 14; 579: 621-36.

36. Douglas NJ, Thomas S, Jan MA. Clinical value of polysomnography. Lancet, 1992 Feb 1; 339: P347-50.

37. Luck SJ, Kappenman ES. The Oxford Handbook of Event-Related Potential Components. Oxford University Press, USA; 2012.

38. Luck SJ. An Introduction to the Event-Related Potential Technique. MIT Press; 2014.

39. Martin BA, Tremblay KL, Korczak P. Speech evoked potentials: from the laboratory to the clinic. Ear Hear, 2008 Jun; 29: 285-313.

40. Van Dun B, Dillon H, Seeto M. Estimating hearing thresholds in hearing-impaired adults through objective detection of cortical auditory evoked potentials. J Am Acad Audiol, 2015 Apr 1; 26: 370-83.

41. Li LP-H, Chen K-C, Lee P-L, et al. Neuromagnetic index of hemispheric asymmetry predicting long-term outcome in sudden hearing loss. NeuroImage, 2013 Jan; 64: 356-64.

42. Ponton CW, Vasama J-P, Tremblay K, Khosla D, Kwong B, Don M. Plasticity in the adult human central auditory system: evidence from late-onset profound unilateral deafness. Hear Res, 2001 Apr; 154: 32-44.

43. Kral A, Sharma A. Developmental neuroplasticity after cochlear implantation. Trends Neurosci, 2012 Feb; 35: 111-22.

44. Paluch P, Kochański B, Ganc M, et al. Early general development and central auditory system maturation in children with cochlear implants: a case series. Int J Pediatr Otorhinolaryngol, 2019 Nov 1; 126:109625.

45. Näätänen R, Paavilainen P, Rinne T, Alho K. The mismatch negativity (MMN) in basic research of central auditory processing: a review. Clin Neurophysiol, 2007 Dec; 118: 2544-90.

46. Näätänen R, Lehtokoski A, Lennes M, et al. Language-specific phoneme representations revealed by electric and magnetic brain responses. Nature, 1997 Jan 30; 385: 432-4.

47. McDermott JH. The cocktail party problem. Curr Biol, $2009 \mathrm{Dec}$; 19: R1024-7.

48. Hillyard SA, Hink RF, Schwent VL, Picton TW. Electrical Signs of Selective Attention in the Human Brain. Science, 1973 Oct 12;182:177-80.

49. Aimoni C, Crema L, Savini S, et al. Hearing threshold estimation by auditory steady state responses (ASSR) in children. Acta Otorhinolaryngol Ital, 2018 Aug; 38: 361-368.

50. Picton TW, John MS, Dimitrijevic A, Purcell D. Human auditory steady-state responses. Int J Audiol, 2003 Jan; 42: 177-219.

51. Kaneko K, Fujiki N, Hari R. Binaural interaction in the human auditory cortex revealed by neuromagnetic frequency tagging: no effect of stimulus intensity. Hear Res, 2003 Sep; 183:1-6.

52. Undurraga JA, Haywood NR, Marquardt T, McAlpine D. Neural representation of interaural time differences in humans: an objective measure that matches behavioural performance. JARO, 2016 Dec;17:591-607.

53. Etard O, Reichenbach T. Neural speech tracking in the theta and in the delta frequency band differentially encode clarity and comprehension of speech in noise. J Neurosci, 2019 May 20; 39:5750-9.

54. Somers B, Verschueren E, Francart T. Neural tracking of the speech envelope in cochlear implant users. J Neural Eng, 2018 Nov 16; 16:016003. 
55. Vanheusden FJ, Kegler M, Ireland K, et al. Hearing aids do not alter cortical entrainment to speech at audible levels in mildto-moderately hearing-impaired subjects. Front Hum Neurosci, 2020; 14.

56. Etard O, Kegler M, Braiman C, Forte AE, Reichenbach T. Decoding of selective attention to continuous speech from the human auditory brainstem response. NeuroImage, 2019;200:1-11.

57. Ashton H, Reid K, Marsh R, Johnson I, Alter K, Griffiths T. High frequency localised "hot spots" in temporal lobes of patients with intractable tinnitus: a quantitative electroencephalographic (QEEG) study. Neurosci Lett, 2007 Oct; 426:23-8.

58. Song J-J, Punte AK, De Ridder D, Vanneste S, Van de Heyning P. Neural substrates predicting improvement of tinnitus after cochlear implantation in patients with single-sided deafness. Hear Res, 2013 May; 299:1-9.

59. Milner R, Lewandowska M, Ganc M, Włodarczyk E, Grudzień D, Skarżyński H. Abnormal resting-state quantitative electroencephalogram in children with central auditory processing disorder: a pilot study. Front Neurosci, 2018 May 11;12.

60. Güntensperger D, Thüring C, Meyer M, Neff P, Kleinjung T. Neurofeedback for tinnitus treatment: review and current concepts. Front Aging Neurosci, 2017 Dec 1; 9.

61. Milner R, Lewandowska M, Ganc M, Cieśla K, Niedziałek I, Skarżyński H. Slow cortical potential neurofeedback in chronic tinnitus therapy: a case report. Appl Psychophysiol Biofeedback, 2015 Oct 12; 41: 225-49.

62. Lindquist MA, Meng Loh J, Atlas LY, Wager TD. Modeling the hemodynamic response function in fMRI: efficiency, bias and mis-modeling. Math Brain Imaging, 2009 Mar 1; 45: S187-98.

63. Huettel SA, Song AW, McCarthy G. Functional Magnetic Resonance Imaging. 2nd edition. Sunderland, Mass: Sinauer Associates; 2008.

64. Gulban OF, Goebel R, Moerel M, et al. Improving a probabilistic cytoarchitectonic atlas of auditory cortex using a novel method for inter-individual alignment. bioRxiv. 2020 Jan 1;2020.03.30.015313.

65. Barisano G, Sepehrband F, Ma S, et al. Clinical 7 T MRI: are we there yet? A review about magnetic resonance imaging at ultra-high field. Br J Radiol, 2019; 92: 20180492.

66. Kraff O, Quick HH. 7T: physics, safety, and potential clinical applications. J Magn Reson Imaging, 2017 Dec; 46: 1573-89.

67. Ravicz ME, Melcher JR, Kiang NY-S. Acoustic noise during functional magnetic resonance imaging. J Acoust Soc Am, 2000 Oct; 108: 1683-96.

68. Seifritz E, Di Salle F, Esposito F, Herdener M, Neuhoff JG, Scheffler K. Enhancing BOLD response in the auditory system by neurophysiologically tuned fMRI sequence. NeuroImage, 2006 Feb; 29: 1013-22.

69. Talavage TM, Sereno MI, Melcher JR, Ledden PJ, Rosen BR, Dale AM. Tonotopic organization in human auditory cortex revealed by progressions of frequency sensitivity. J Neurophysiol, 2004 Mar; 91: 1282-96.

70. Woods DL, Stecker GC, Rinne T, et al. Functional maps of human auditory cortex: effects of acoustic features and attention. PLOS One, 2009 Apr 13; 4: e5183.

71. Hertz U, Amedi A. Flexibility and stability in sensory processing revealed using visual-to-auditory sensory substitution. Cereb Cortex, 2015 Aug; 25: 2049-64.

72. Humphries C, Liebenthal E, Binder JR. Tonotopic organization of human auditory cortex. NeuroImage, 2010 Apr; 50: 1202-11.

73. Langers DRM, van Dijk P, Schoenmaker ES, Backes WH. fMRI activation in relation to sound intensity and loudness. NeuroImage, 2007 Apr; 35: 709-18.
74. Striem-Amit E, Hertz U, Amedi A. Extensive cochleotopic mapping of human auditory cortical fields obtained with phase-encoding fMRI. PLOS One, 2011 Mar 23; 6: e17832.

75. Wessinger CM, VanMeter J, Tian B, Van Lare J, Pekar J, Rauschecker JP. Hierarchical organization of the human auditory cortex revealed by functional magnetic resonance imaging. J Cogn Neurosci, 2001 Jan; 13: 1-7.

76. Peelle JE. Methodological challenges and solutions in auditory functional magnetic resonance imaging. Front Neurosci, 2014; 8: 253.

77. Sorger B, Kamp T, Weiskopf N, Peters JC, Goebel R. When the brain takes 'BOLD' steps: real-time fMRI neurofeedback can further enhance the ability to gradually self-regulate regional brain activation. Neurosci, 2018 May 15; 378: 71-88.

78. Sorger B, Goebel R. Real-time fMRI for brain-computer interfacing. Handb Clin Neurol, 2020; 168: 289-302.

79. Mather M, Cacioppo JT, Kanwisher N. How fMRI can inform cognitive theories. Perspect Psychol Sci, 2013 Jan; 8: 108-13.

80. DeYoe EA, Raut RV. Visual mapping using BOLD fMRI. Neuroimaging Clin N Am, 2014 Nov; 24: 573-84.

81. Hall D, Lanting C, Hartley D. Using fMRI to examine central auditory plasticity. In: Papageorgiou TD, Christopoulos GI, Smirnakis SM, editors. Advanced Brain Neuroimaging Topics in Health and Disease - Methods and Applications. InTech Open; 2014.

82. Price CJ. A review and synthesis of the first 20 years of PET and fMRI studies of heard speech, spoken language and reading. NeuroImage, 2012 Aug; 62: 816-47.

83. Talavage TM, Gonzalez-Castillo J, Scott SK. Auditory neuroimaging with fMRI and PET. Hear Res, 2014 Jan; 307: 4-15.

84. Binder JR. fMRI of language systems. In: Filippi M, editor. Neuromethods: fMRI Techniques and Protocols. New York: Springer; 2016. p. 355-85.

85. Black DF, Vachha B, Mian A, et al. American Society of Functional Neuroradiology: recommended fMRI paradigm algorithms for presurgical language assessment. Am J Neuroradiol, 2017 Oct 1; 38: E65-73.

86. Zubicaray GI de, Schiller NO. The Oxford Handbook of Neurolinguistics. Oxford University Press; 2019.

87. Skarzynski PH, Wolak T, Skarzynski H, et al. Application of the functional magnetic resonance imaging (fMRI) for the assessment of the primary auditory cortex function in partial deafness patients: a preliminary study. J Int Adv Otol, 2013; 9: 153-60.

88. Wolak T, Cieśla K, Wojcik J, Skarzynski H. Effect of sound intensity on level of activation in auditory cortex as measured by fMRI. J Hear Sci, 2017; 7: 20-7.

89. Wolak T, Cieśla K, Lorens A, et al. Tonotopic organisation of the auditory cortex in sloping sensorineural hearing loss. Hear Res, 2017 Nov; 355: 81-96.

90. Wolak T, Cieśla K, Rusiniak M, et al. Influence of acoustic overstimulation on the central auditory system: a functional magnetic resonance imaging (fMRI) study. Med Sci Monit, 2016; 22: 4623-35.

91. Ahveninen J, Chang W-T, Huang S, et al. Intracortical depth analyses of frequency-sensitive regions of human auditory cortex using 7T fMRI. NeuroImage, 2016 Dec 1; 143: 116-27.

92. Chang KH, Thomas JM, Boynton GM, Fine I. Reconstructing tone sequences from functional magnetic resonance imaging blood-oxygen level dependent responses within human primary auditory cortex. Front Psychol, 2017; 8: 1983.

93. Frühholz S, Trost W, Grandjean D, Belin P. Neural oscillations in human auditory cortex revealed by fast fMRI during auditory perception. NeuroImage, 2020 Feb 15; 207: 116401. 
94. Biswal B, Zerrin Yetkin F, Haughton VM, Hyde JS. Functional connectivity in the motor cortex of resting human brain using echo-planar MRI. Magn Reson Med, 1995 Oct; 34: 537-41.

95. Pluta A, Wolak T, Czajka N, et al. Reduced resting-state brain activity in the default mode network in children with (central) auditory processing disorders. Behav Brain Funct, 2014 Sep 26; 10: 33 .

96. Fitzhugh MC, Hemesath A, Schaefer SY, Baxter LC, Rogalsky C. Functional connectivity of Heschl's gyrus associated with agerelated hearing loss: a resting-state fMRI study. Front Psychol, 2019 Nov 6; 10: 2485.

97. Puschmann S, Thiel CM. Changed crossmodal functional connectivity in older adults with hearing loss. Cortex, 2017 Jan 1; 86: 109-22.

98. Wolak T, Cieśla K, Pluta A, Włodarczyk E, Biswal B, Skarżyński H Altered functional connectivity in patients with sloping sensorineural hearing loss. Front Hum Neurosci, 2019 Aug 22; 13: 284.

99. Giraud A-L, Lee H-J. Predicting cochlear implant outcome from brain organisation in the deaf. Restor Neurol Neurosci, 2007; 255: 381-90.

100. Lazard DS, Lee H-J, Truy E, Giraud A-L. Bilateral reorganization of posterior temporal cortices in post-lingual deafness and its relation to cochlear implant outcome. Hum Brain Mapp, 2013 May; 34: 1208-19.

101. Todt I, Tittel A, Ernst A, Mittmann P, Mutze S. Pain free 3 T MRI scans in cochlear implantees. Otol Neurotol, 2017 Dec; 38: e401-4.

102. Zhen E, Kuthubutheen J, Misso D, Rodrigues S, Thompson A. 3 Tesla MRI brain scanning under general anaesthesia in a paediatric 3 Tesla-compatible cochlear implant recipient, first reported case: clinical considerations and implications for future practice. Int J Pediatr Otorhinolaryngol, 2020 Mar 21; 133: 110015.

103. Pérez-Juste I, Faza ON. Interaction of radiation with matter. In: Structure Elucidation in Organic Chemistry. John Wiley \& Sons, Ltd; 2014. p. 1-26.

104. Shah N, Cerussi A, Eker C, et al. Noninvasive functional optical spectroscopy of human breast tissue. Proc Natl Acad Sci U.S.A. 2001 Apr 10; 98: 4420-5.

105. Villringer A, Chance B. Non-invasive optical spectroscopy and imaging of human brain function. Trends Neurosci, 1997 Oct 1; 20: 435-42.

106. Nippert AR, Biesecker KR, Newman EA. Mechanisms mediating functional hyperemia in the brain. Neurosci Rev J, 2018 Feb; 24: 73-83.

107. Pinti P, Tachtsidis I, Hamilton A, et al. The present and future use of functional near-infrared spectroscopy (fNIRS) for cognitive neuroscience. Ann N Y Acad Sci, 2020 Mar; 1464(1): 5-29.

108. Jobsis FF. Noninvasive, infrared monitoring of cerebral and myocardial oxygen sufficiency and circulatory parameters. Science, 1977 Dec 23; 198: 1264-7.

109. Scholkmann F, Kleiser S, Metz AJ, et al. A review on continuous wave functional near-infrared spectroscopy and imaging instrumentation and methodology. NeuroImage, 2014; 85: 6-27.

110. Peelle JE. Optical neuroimaging of spoken language. Lang Cogn Neurosci, 2017 Aug 9; 32: 847-54.

111. van Gerven M, Farquhar J, Schaefer R, et al. The brain-computer interface cycle. J Neural Eng, 2009 Sep 1; 6: 041001.

112. Culver JP, Ntziachristos V, Holboke MJ, Yodh AG. Optimization of optode arrangements for diffuse optical tomography: a singular-value analysis. Opt Lett, 2001; 26: 701-3.
113. Hassanpour MS, Eggebrecht AT, Culver JP, Peelle JE. Mapping cortical responses to speech using high-density diffuse optical tomography. NeuroImage, 2015 Aug 15; 117: 319-26.

114. Haeussinger FB, Heinzel S, Hahn T, Schecklmann M, Ehlis A-C, Fallgatter AJ. Simulation of near-infrared light absorption considering individual head and prefrontal cortex anatomy: implications for optical neuroimaging. PLOS One, 2011 Oct 24; 6: e26377.

115. Koch SP, Habermehl C, Mehnert J, et al. High-resolution optical functional mapping of the human somatosensory cortex. Front Neuroenergetics, 2010 Jun 14; 2: 12.

116. White BR, Culver JP. Quantitative evaluation of high-density diffuse optical tomography: in vivo resolution and mapping performance. J Biomed Opt, 2010; 15: 026006.

117. Chitnis D, Cooper RJ, Dempsey L, et al. Functional imaging of the human brain using a modular, fibre-less, high-density diffuse optical tomography system. Biomed Opt Express, 2016; 7: 4275-88.

118. Eggebrecht AT, Ferradal SL, Robichaux-Viehoever A, et al. Mapping distributed brain function and networks with diffuse optical tomography. Nat Photonics, 2014 Jun; 8: 448-54.

119. Tsuzuki D, Dan I. Spatial registration for functional near-infrared spectroscopy: from channel position on the scalp to cortical location in individual and group analyses. NeuroImage, 2014 Jan 15; 85 Pt 1: 92-103.

120. Strangman G, Boas DA, Sutton JP. Non-invasive neuroimaging using near-infrared light. Biol Psychiatry, 2002 Oct 1; 52: 679-93.

121. Wheelock MD, Culver JP, Eggebrecht AT. High-density diffuse optical tomography for imaging human brain function. Rev Sci Instrum, 2019; 90: 51101.

122. Kolasa G, Rybakowski F. Application of functional near-infrared spectroscopy in psychiatry and physical activity studies. Pharmacother Psychiatry Neurol, 2019 Jan 1; 35: 131-45.

123. Mihara M, Miyay I. Review of functional near-infrared spectroscopy in neurorehabilitation. Neurophotonics, 2016 Jul; 3: 031414.

124. van de Rijt LPH, van Wanrooij MM, Snik AFM, Mylanus EAM, van Opstal AJ, Roye A. Measuring cortical activity during auditory processing with functional near-infrared spectroscopy. J Hear Sci, 2018; 8: 9-18.

125. Sevy ABG, Bortfeld H, Huppert TJ, Beauchamp MS, Tonini RE, Oghalai JS. Neuroimaging with near-infrared spectroscopy demonstrates speech-evoked activity in the auditory cortex of deaf children following cochlear implantation. Hear Res, 2010; 270: 39-47.

126. van de Rijt LPH, van Opstal AJ, Mylanus EAM, et al. Temporal cortex activation to audiovisual speech in normal-hearing and cochlear implant users measured with functional near-infrared spectroscopy. Front Hum Neurosci, 2016 Feb 11; 10: 48.

127. Schroeder ML, Fishell AK, Sherafati A, Svoboda AM, Culver JP, Eggebrecht AT. Cortical activity underlying overt and covert language generation measured using high-density diffuse optical tomography. Proc SPIE-OSA, 2019. https://doi. org/10.1117/12.2526854

128. Santosa H, Hong MJ, Hong K-S. Lateralization of music processing with noises in the auditory cortex: an fNIRS study. Front Behav Neurosci, 2014; 8: 418.

129. Hong K-S, Santosa H. Decoding four different sound-categories in the auditory cortex using functional near-infrared spectroscopy. Hear Res, 2016 Mar 1; 333: 157-66. 
130. Lawrence RJ, Wiggins IM, Anderson CA, Davies-Thompson J, Hartley DEH. Cortical correlates of speech intelligibility measured using functional near-infrared spectroscopy (fNIRS). Hear Res, 2018 Dec 1; 370: 53-64.

131. Pollonini L, Olds C, Abaya H, Bortfeld H, Beauchamp MS, Oghalai JS. Auditory cortex activation to natural speech and simulated cochlear implant speech measured with functional nearinfrared spectroscopy. Hear Res, 2014 Mar; 309: 84-93.

132. Moriai-Izawa A, Dan H, Dan I, et al. Multichannel fNIRS assessment of overt and covert confrontation naming. Brain Lang, 2012 Jun 1; 121: 185-93.

133. Wijayasiri P, Hartley DEH, Wiggins IM. Brain activity underlying the recovery of meaning from degraded speech: a functional near-infrared spectroscopy (fNIRS) study. Hear Res, 2017 Aug; 351: 55-67.

134. McDonald NM, Perdue KL, Eilbott J, Loyal J, Shic F, Pelphrey KA. Infant brain responses to social sounds: a longitudinal functional near-infrared spectroscopy study. Dev Cogn Neurosci, 2019 Apr 1; 36: 100638.

135. Cristia A, Minagawa-Kawai Y, Egorova N, et al. Neural correlates of infant accent discrimination: an fNIRS study. Dev Sci, 2014 Jul; 17: 628-35.

136. Olds C, Pollonini L, Abaya $\mathrm{H}$, et al. Cortical activation patterns correlate with speech understanding after cochlear implantation. Ear Hear, 2016; 37: e160-72.

137. Bisconti S, Shulkin M, Hu X, Basura GJ, Kileny PR, Kovelman I. Functional near-infrared spectroscopy brain imaging investigation of phonological awareness and passage comprehension abilities in adult recipients of cochlear implants. J Speech Lang Hear Res, 2016; 59: 239-53.

138. Chen L-C, Sandmann P, Thorne JD, Bleichner MG, Debener S. Cross-modal functional reorganization of visual and auditory cortex in adult cochlear implant users identified with fNIRS. Neural Plast, 2016; 2016:4382656.

139. Dewey RS, Hartley DEH. Cortical cross-modal plasticity following deafness measured using functional near-infrared spectroscopy. Hear Res, 2015; 325: 55-63.

140. Anderson CA, Wiggins IM, Kitterick PT, Hartley DEH. Adaptive benefit of cross-modal plasticity following cochlear implantation in deaf adults. Proc Natl Acad Sci U.S.A, 2017 Sep 19; 114: 10256-61.

141. San Juan J, Hu X-S, Issa M, et al. Tinnitus alters resting state functional connectivity (RSFC) in human auditory and nonauditory brain regions as measured by functional near-infrared spectroscopy (fNIRS). PLOS One, 2017 Jun 12; 12: e0179150.

142. Paans AMJ, van Waarde A, Elsinga PH, Willemsen ATM, Vaalburg W. Positron emission tomography: the conceptual idea using a multidisciplinary approach. Methods, 2002 Jul; 27: 195-207.

143. Huang Y-Y. An Overview of PET Radiopharmaceuticals in Clinical Use: Regulatory, Quality and Pharmacopeia Monographs of the United States and Europe. InTech Open, 2018. DOI: 10.5772/intechopen.79227

144. Portnow LH, Vaillancourt DE, Okun MS. The history of cerebral PET scanning: from physiology to cutting-edge technology. Neurology, 2013 Mar 4; 80: 952-6.

145. Sander CY, Hesse S. News and views on in-vivo imaging of neurotransmission using PET and MRI. Q J Nucl Med Mol Imaging, 2017 Dec; 61: 414-28.

146. Kameyama M, Murakami K, Jinzaki M. Comparison of [15O] $\mathrm{H} 2 \mathrm{O}$ positron emission tomography and functional magnetic resonance imaging in activation studies. World J Nucl Med, 2016; 15: 3-6.
147. Ruytjens L, Willemsen ATM, Van Dijk P, Wit HP, Albers FWJ. Functional imaging of the central auditory system using PET. Acta Otolaryngol, 2006 Jan; 126: 1236-44.

148. Horwitz B, Braun AR. Brain network interactions in auditory, visual and linguistic processing. Brain Lang, 2004 May; 89: 377-84.

149. Wong D, Pisoni DB, Learn J, Gandour JT, Miyamoto RT, Hutchins GD. PET imaging of differential cortical activation by monaural speech and nonspeech stimuli. Hear Res, 2002 Apr; 166: 9-23.

150. Petacchi A, Kaernbach C, Ratnam R, Bower JM. Increased activation of the human cerebellum during pitch discrimination: a positron emission tomography (PET) study. Hear Res, 2011 Dec; 282: 35-48.

151. Satoh M, Nagata K, Tomimoto H. Sound richness of music might be mediated by color perception: a PET study. Behav Neurol, 2015; 2015: 1-10.

152. Lauter JL, Herscovitch P, Formby C, Raichle ME. Tonotopic organization in human auditory cortex revealed by positron emission tomography. Hear Res, 1985 Jan; 20: 199-205.

153. Strelnikov K, Marx M, Lagleyre S, Fraysse B, Deguine O, Barone P. PET-imaging of brain plasticity after cochlear implantation. Hear Res, 2015 Apr; 322: 180-7.

154. Berding G, Wilke F, Rode T, et al. Positron emission tomography imaging reveals auditory and frontal cortical regions involved with speech perception and loudness adaptation. PLOS One, 2015 Jun 5; 10: e0128743.

155. Giraud A-L, Price CJ, Graham JM, Frackowiak RSJ. Functional plasticity of language-related brain areas after cochlear implantation. Brain, 2001 Jul 1; 124: 1307-16.

156. Limb CJ, Molloy AT, Jiradejvong P, Braun AR. Auditory cortical activity during cochlear implant-mediated perception of spoken language, melody, and rhythm. JARO, 2010 Mar; 11: 133-43.

157. Mortensen MV, Mirz F, Gjedde A. Restored speech comprehension linked to activity in left inferior prefrontal and right temporal cortices in postlingual deafness. NeuroImage, 2006 Jun; 31: 842-52.

158. Naito Y, Okazawa H, Honjo I, et al. Cortical activation with sound stimulation in cochlear implant users demonstrated by positron emission tomography. Cogn Brain Res, 1995 Jul; 2: 207-14.

159. Naito Y, Tateya I, Fujiki N, et al. Increased cortical activation during hearing of speech in cochlear implant users. Hear Res, 2000 May; 143: 139-46.

160. Okazawa H, Naito Y, Yonckura Y, et al. Cochlear implant efficiency in pre- and postlingually deaf subjects: a study with H215O and PET. Brain, 1996 Aug 1; 119: 1297-306.

161. Petersen B, Gjedde A, Wallentin M, Vuust P. Cortical plasticity after cochlear implantation. Neural Plast, 2013; 2013: 1-11.

162. Song J-J, Mertens G, Deleye S, et al. Neural substrates of conversion deafness in a cochlear implant patient: a molecular imaging study using H215O-PET. Otol Neurotol, 2014 Dec; 35: 1780-4.

163. Strelnikov K, Rouger J, Lagleyre S, et al. Increased audiovisual integration in cochlear-implanted deaf patients: independent components analysis of longitudinal positron emission tomography data. Eur J Neurosci, 2015 Mar; 41: 677-85.

164. Strelnikov K, Rouger J, Eter E, et al. Binaural stimulation through cochlear implants in postlingual deafness: a positron emission tomographic study of word recognition. Otol Neurotol, 2011 Oct; 32: 1210-7. 
165. Strelnikov K, Rouger J, Demonet J-F, et al. Visual activity predicts auditory recovery from deafness after adult cochlear implantation. Brain, 2013 Dec; 136: 3682-95.

166. Wong D, Miyamoto RT, Pisoni DB, Sehgal M, Hutchins GD. PET imaging of cochlear-implant and normal-hearing subjects listening to speech and nonspeech. Hear Res, 1999 Jun; 132: 34-42.

167. Giraud A-L, Truy E. The contribution of visual areas to speech comprehension: a PET study in cochlear implants patients and normal-hearing subjects. Neuropsychologia, 2002 Jan; 40: 1562-9.

168. Coez A, Zilbovicius M, Ferrary E, et al. Cochlear implant benefits in deafness rehabilitation: PET study of temporal voice activations. J Nucl Med, 2007 Dec 12; 49: 60-7.

169. Rouger J, Lagleyre S, Démonet J-F, Fraysse B, Deguine O, Barone P. Evolution of crossmodal reorganization of the voice area in cochlear-implanted deaf patients. Hum Brain Mapp, 2012 Aug; 33: 1929-40.

170. Suh M-W, Park KT, Lee H-J, Lee JH, Chang SO, Oh SH. Factors contributing to speech performance in elderly cochlear implanted patients: an FDG-PET study: a preliminary study. J Int Adv Otol, 2015 Sep 17; 11: 98-103.

171. Langguth B, Eichhammer P, Kreutzer A, et al. The impact of auditory cortex activity on characterizing and treating patients with chronic tinnitus: first results from a PET study. Acta Otolaryngol, 2006 Jan; 126: 84-8.

172. Mennemeier M, Chelette KC, Allen S, et al. Variable changes in PET activity before and after rTMS treatment for tinnitus. Laryngoscope, 2011 Apr; 121: 815-22.

173. Schecklmann M, Landgrebe M, Poeppl TB, et al. Neural correlates of tinnitus duration and distress: a positron emission tomography study. Hum Brain Mapp, 2011; 34: 233-40.

174. Guinchard A-C, Ghazaleh N, Saenz M, et al. Study of tonotopic brain changes with functional MRI and FDG-PET in a patient with unilateral objective cochlear tinnitus. Hear Res, 2016 Nov; 341: 232-9.

175. Lee JS, Lee DS, Oh SH, et al. PET evidence of neuroplasticity in adult auditory cortex of postlingual deafness. J Nucl Med, 2003; 44: 1435-9.

176. Okuda T, Nagamachi S, Ushisako Y, Tono T. Glucose metabolism in the primary auditory cortex of postlingually deaf patients: an FDG-PET study. ORL, 2013; 75: 342-9.

177. Verger A, Roman S, Chaudat R-M, et al. Changes of metabolism and functional connectivity in late-onset deafness: evidence from cerebral 18 F-FDG-PET. Hear Res, 2017 Sep; 353 $8-16$.

178. Ito J, Iwasaki Y, Sakakibara J, Yonekura Y. Positron emission tomography of auditory sensation in deaf patients and patients with cochlear implants. Ann Otol Rhinol Laryngol, 1993 Oct; 102: 797-801.

179. Lee H-J, Giraud A-L, Kang E, et al. Cortical activity at rest predicts cochlear implantation outcome. Cereb Cortex, 2007 Apr; 17: 909-17.

180. Yoshida H, Takahashi H, Kanda Y, Chiba K. PET-CT observations of cortical activity in pre-lingually deaf adolescent and adult patients with cochlear implantation. Acta Otolaryngol, 2017 May 4; 137: 464-70.
181. Green KMJ, Julyan PJ, Hastings DL, Ramsden RT. Cortical activations in sequential bilateral cochlear implant users. Cochlear Implants Int, $2011 \mathrm{Feb}$; 12: 3-9.

182. Kang E, Lee DS, Kang H, et al. Neural changes associated with speech learning in deaf children following cochlear implantation. NeuroImage, 2004 Jul; 22: 1173-81.

183. Fujiwara K, Naito Y, Senda M, et al. Brain metabolism of children with profound deafness: a visual language activation study by $18 \mathrm{~F}$-fluorodeoxyglucose positron emission tomography. Acta Otolaryngol, 2008 Jan; 128: 393-7.

184. Liu S, Cai W, Liu S, et al. Multimodal neuroimaging computing: a review of the applications in neuropsychiatric disorders. Brain Inform, 2015 Sep; 2: 167-80.

185. Putze F, Hesslinger S, Tse C-Y, et al. Hybrid fNIRS-EEG based classification of auditory and visual perception processes. Front Neurosci, 2014; 8.

186. Pillai RLI, Bartlett EA, Ananth MR, et al. Examining the underpinnings of loudness dependence of auditory evoked potentials with positron emission tomography. NeuroImage, 2020 Jun 1; 213: 116733.

187. Huotilainen M, Winkler I, Alho K, et al. Combined mapping of human auditory EEG and MEG responses. Electroencephalogr Clin Neurophysiol, 1998 Jul; 108: 370-9.

188. Huster RJ, Debener S, Eichele T, Herrmann C. Methods for simultaneous EEG-fMRI: an introductory review. J Neurosci, 2012 May 2; 32(18): 6053-60.

189. Horovitz SG, Skudlarski P, Gore JC. Correlations and dissociations between BOLD signal and P300 amplitude in an auditory oddball task: a parametric approach to combining fMRI and ERP. Magn Reson Imaging, 2002 May 1; 20: 319-25.

190. Kirino E, Hayakawa Y, Inami R, Inoue R, Aoki S. Simultaneous fMRI-EEG-DTI recording of MMN in patients with schizophrenia. PLOS One, 2019 May 9; 14: e0215023.

191. Mangalathu-Arumana J, Beardsley SA, Liebenthal E. Withinsubject joint independent component analysis of simultaneous $\mathrm{fMRI} / \mathrm{ERP}$ in an auditory oddball paradigm. NeuroImage, 2012 May 1; 60(4): 2247-57.

192. Rusiniak M, Lewandowska M, Wolak T, et al. A modified oddball paradigm for investigation of neural correlates of attention: a simultaneous ERP-fMRI study. Magn Reson Mater Phy, 2013 Dec; 26: 511-26.

193. Milner R, Rusiniak M, Lewandowska M, et al. Towards neural correlates of auditory stimulus processing: a simultaneous auditory evoked potentials and functional magnetic resonance study using an odd-ball paradigm. Med Sci Monit, 2014; 20: 35-46.

194. Abreu R, Leal A, Figueiredo P. EEG-informed fMRI: a review of data analysis methods. Front Hum Neurosci, 2018 Feb 6; 12.

195. Blinowska K, Müller-Putz G, Kaiser V, et al. Multimodal imaging of human brain activity: rational, biophysical aspects and modes of integration. Comput Intell Neurosci, 2009; 2009: 1-10. 